\title{
A model of a discretely supported railway track based on a 2.5D finite element approach
}

\author{
Xianying Zhang ${ }^{1}$, David J Thompson ${ }^{1}$, Qi Li ${ }^{2}$, Dimitrios Kostovasilis ${ }^{1}$, Martin G R Toward ${ }^{1}$, \\ Giacomo Squicciarini ${ }^{1}$, Jungsoo Ryue ${ }^{3}$ \\ ${ }^{1}$ Institute of Sound and Vibration Research, University of Southampton, Southampton \\ SO17 1BJ, UK \\ ${ }^{2}$ Department of Bridge Engineering, Tongji University, 1239 Siping Road, Shanghai 200092, \\ China
}

${ }^{3}$ School of Naval Architecture and Ocean Engineering, University of Ulsan, Ulsan 44610, South Korea

\begin{abstract}
The dynamic properties of a railway track are important for both the generation of rolling noise and the development of rail corrugation. A conventional track consists of long rails mounted periodically on transverse sleepers and supported in ballast. In order to improve the predictions of the noise and vibration of the track, a model of a discretely supported track is proposed based on the so-called 2.5 dimensional (2.5D) finite element approach, which is used to model an infinite free rail. This is coupled to a finite number of sleepers, by means of an array of springs representing each rail pad, using a receptance coupling method. The sleepers are represented by flexible beams, supported on an elastic foundation. Results are presented in terms of the point mobility and track decay rate and these are compared with the corresponding field measurements for two tracks, one with soft rail pads and one with stiff rail pads. Very good agreement is found between the predictions and the measurement results, especially for the track with soft rail pads. The flexible sleeper model is shown to give improved results compared with a rigid mass model, especially for the track with stiff rail pads.
\end{abstract}

Keywords: discretely supported track, waveguide finite element, 2.5 dimension, rail, flexible sleepers, railway track dynamics, rail pad, track decay rate

\section{Introduction}

The high frequency dynamic behaviour of a railway track is of importance for the generation of railway rolling noise [1]. It also has an important contribution to the generation of rail 
corrugation via the dynamic interaction with the wheels. In addition to the rails, a typical ballasted track consists of rail pads, sleepers and ballast; the rail vibration is influenced by these components that support the rail. A suitable model for the track dynamics should consider the interactions among the different components as well as the discrete nature of the support. For use in noise predictions a frequency range up to at least $5000 \mathrm{~Hz}$ should be considered [1].

Many authors have used Euler-Bernoulli or Timoshenko beam theories to represent the vertical dynamics of the rail, often assuming an equivalent continuous support [2-5]. Although these models are relatively successful for the vertical dynamics, the lateral response of the rail is not so well predicted by these beam models due to the omission of torsion $[1,6]$. Moreover, simple beam models cannot be used reliably at high frequencies, where crosssectional deformation becomes important. This has been observed through experiments, from which it was found that the cross-section deforms significantly above about $1500 \mathrm{~Hz}$ [7]. Multiple beam configurations have been used to explore both the vertical and lateral vibration of the rails to overcome this limitation $[8,9]$ but they are based on approximations.

In practice, although the continuously supported models give a good approximation to the overall trends in the dynamic behaviour, the discrete nature of the track supports provided by the sleepers has a significant effect. The largest effect occurs around the pinned-pinned frequency, at which the sleeper spacing corresponds to half a bending wavelength in the rail. The pinned-pinned frequency has been particularly associated with some forms of rail corrugation, which results in excessive noise and structural damage to the track [10]. Grassie et al. [11] proposed a discretely supported track model, in which the sleepers were represented by concentrated masses attached at regular intervals to a uniform Euler beam (the rail) by damped springs (the rail pads) and supported by a second layer of damped springs (the ballast). The results showed a strong resonance peak at the pinned-pinned frequency for excitation between the sleepers and a corresponding dip for excitation above the sleepers. The track was also modelled as a periodically supported Euler-Bernoulli beam by Tassilly [12], who produced dispersion relations of wavenumber against frequency, showing stop and pass bands associated with the periodic supports. Ono and Yamada [13] also modelled the rail using an Euler-Bernoulli beam and studied the propagation of vibration into the ballast and ground. Heckl [14] proposed a discretely supported track model, in which an infinitely long Timoshenko beam was used to represent the rail. This infinite beam was supported over a finite length at discrete points by spring/mass/spring systems representing the rail supports 
(railpad, sleeper and ballast). Each support system was considered to exert a point force on the rail, which meant the track could be represented simply as a beam with many point forces acting on it. By using a finite number of discrete supports the effect of random spacing could also be studied. This method was incorporated into a multiple-beam model by $\mathrm{Wu}$ and Thompson $[8,15]$ to explore the vertical and lateral vibration response of a discretely supported rail. Heckl [16] also developed a model for an infinite beam with infinitely many periodic supports to study the coupled waves in all three directions in the beam.

The finite element (FE) technique can also be used to include the effects of cross-sectional deformation in the track response at high frequencies [7,17-19]. In references [17] and [18], a FE model of a finite length of rail was established; by applying symmetric or antisymmetric boundary conditions at both ends of the finite length, the modes of vibration obtained correspond to the waves in an infinite rail, allowing the dispersion behaviour to be determined. This was carried out for a freely suspended rail [17] and for one on continuous supports [18]. However, such an approach cannot be used to find the forced response. The FE method and its application to rails was briefly explained by Knothe et al. [19], and the performance of different models was compared. An FE model of a long length of track with non-reflecting boundaries was also used recently by Betgen et al. [20] to predict the track decay rates.

One of the drawbacks of the conventional FE method is that the computational burden can become large, particularly for a model requiring high-frequency analysis, due to the need to include a considerable length of rail. An alternative numerical method, known as the 2.5 dimensional finite element (2.5D FE) method, has therefore been adopted by a number of authors. This approach is also referred to in the literature as the Semi-Analytical FE (SAFE) method [21] and Waveguide FE method [22,23]. It is used to represent structures which have a two-dimensional (2D) geometry and which are invariant in the third direction. The crosssection can be modelled by a 2D FE mesh with special elements, with the usual assumptions of the shape functions, while a wave solution is assumed in the third direction. Free wave propagation can be determined to obtain the dispersion curves and the forced response can be obtained as a frequency response function. This method has been used to study various structures: rods [24], thin-walled beams [25], rib-stiffened plates [26] and car tyres [22]. It has also been used to study rail vibration. Early relevant work was done by Knothe et al. [19] and Gavric [27] to obtain the free waves propagating in an unsupported rail. Using this method, Ryue et al. [18] determined the waves propagating in a continuously supported rail 
up to $80 \mathrm{kHz}$, while Nilsson et al. [23] calculated the vibration and sound radiation of an infinite continuously supported rail excited by a point force using a coupled 2.5D finite element and boundary element model. Only a single layer of rail pad support representing the rail pad was considered in the track in these studies [18,23]. The dispersion relations and the forced responses of both a free rail and a continuously supported rail were also recently studied by a similar method, where multiple layers of rail support were included [28].

For the track models discussed so far, the sleeper was either omitted, or was modelled as a rigid mass. This simplification ignores the bending modes that monobloc sleepers exhibit in the frequency range above $100 \mathrm{~Hz}$ [1]. Clark et al. [29] developed a theoretical model for the vertical vibration of the track, which consisted of a finite length of rail divided into a number of identical bays supported on flexible sleepers/beams. This model was solved by using a modal analysis technique, but only the symmetric modes of discrete flexible sleepers were considered. Both the symmetric and anti-symmetric bending modes of sleepers were included in a continuous track model by Grassie and Cox [30], where the sleepers were modelled as finite uniform Timoshenko beams supported on a layer of springs. Beam finite elements were also used by Nielsen and Igeland [31] to model the behaviour of flexible sleepers in the track. A simple uniform Timoshenko beam model for a freely suspended sleeper was later proposed by Grassie [32]. The results from this analytical sleeper model were found to agree well with measured natural frequencies, apart from the first bending mode, for which the effect of variations in the sleeper cross-section had the greatest effect. A similar model was used in the TWINS model for rolling noise [33, 34], but including the ballast beneath it represented as an elastic layer.

In the models described above, the rail pad is usually represented as a single point connection between the rail and the sleeper, either as a spring-dashpot pair or a hysteretically damped spring. The area of the rail pad is, however, not negligible. Gry proposed a discretely supported track model by using a combination of a 2.5D FE model and periodic structure theory [35]. The rail support was modelled by a spring-mass-spring system representing the pad, sleeper and ballast. Each sleeper was connected to the rail at three points by springs, each with three directions, located on a single line across the rail. The response of the rail was expanded as a sum over a limited number of waves in the free rail, based on the mode shapes at a single frequency. There were obvious discrepancies between the experimental data and prediction above $1500 \mathrm{~Hz}$, which were attributed to the use of the concentrated supports in the track model. 
Ferrara et al. [36] considered the rail pads as a series of massless spring-damper elements placed across the breadth of the sleeper (i.e. along the rail) in their model, in which the rail was discretised by using Timoshenko beam finite elements. It was shown that the prediction of the rail receptance (displacement for a unit force as a function of frequency) matched the experimental data well; the main difference between a point contact model for the rail pad and a distributed model occurred in the region of the pinned-pinned frequency. The vertical dynamics of a railway track with monobloc sleepers was explored using a 3D finite element model by Oregui et al. [37], in which a length of $14.4 \mathrm{~m}$ was used for the track (24 sleeper bays) with fixed rail ends. The influence of different configurations of springs representing the rail pad was also considered. Mazilu and Leu [38] also investigated the effect of multiple spring-damper systems at each sleeper. Blanco et al. [39] have recently proposed a distributed support model based on a new formulation of Timoshenko beam element which includes an elastic foundation between the rail and the sleeper.

In this paper a new track model is introduced with the aim of improving noise and vibration predictions by including discrete supports as well as rail cross-sectional deformation. This is a discretely supported track model based on an infinitely long rail modelled using a $2.5 \mathrm{D}$ finite element approach [23]. The rail is connected to a finite number of discrete sleepers through multiple connections representing each rail pad. The sleepers are represented by flexible beams and are supported on ballast. Use is made of a receptance coupling method to realize the coupling of the rail and sleeper via a series of springs representing the rail pads. The current model is an improvement and extension of the approach used by Li et al. [40] and is described in Section 2. In Section 3, the vertical and lateral dynamic responses of a ballasted track are predicted by using this discrete track model, and compared with field measurements. Finally, the dependence on various parameters is discussed in Section 4. This considers the effect on the track dynamic behaviour of the models used for the sleeper, the rail and the rail pad.

\section{Modelling of the vibration of a discretely supported track}

There are various ways to model the vibration of a track with discrete supports. The approach adopted here is based on that proposed by Heckl [14] although the formulation is adapted for use with a $2.5 \mathrm{D}$ finite element model of the rail. The discrete rail supports are replaced by corresponding reaction forces, so that the rail is considered as an infinite structure with many point forces acting on it. The 2.5D FE model is used to obtain transfer receptances of the rail 
and the response of the track to an external force can be obtained by using the superposition principle [14].

\subsection{Receptance-coupling method}

For a coupled system, consisting of a source structure and a receiver, connected by flexible isolators, the dynamic response can be determined in terms of the receptances of the various systems at the interface. This is illustrated in general terms in Figure 1. In the present case the source represents the rail, the receiver the sleepers and the isolators the rail pads. An external force $F_{e}$ is applied on the source structure at some arbitrary point $\mathrm{O}$. Interactions occur between the source, the isolator and the receiver as shown in Figure 1. For simplicity this shows vertical interaction forces but at each connection point the forces can act in multiple directions. The isolators are assumed to be massless so that the same forces act on both the source and receiver structures but in opposite directions.

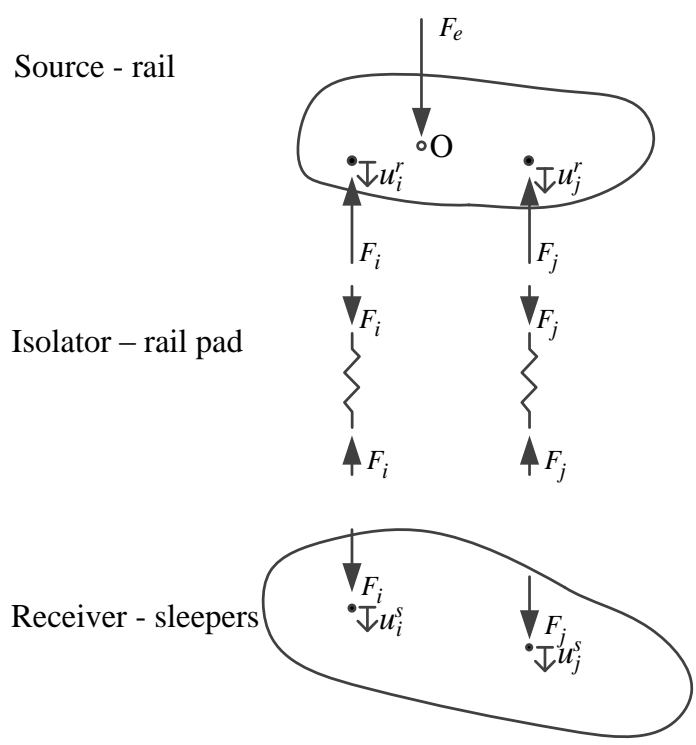

Figure 1 Source and receiver structures coupled at multiple connection points through massless resilient elements

Assuming harmonic motion at circular frequency $\omega$, the displacement of a point $i$ on the source structure (rail) can be expressed as [14] 


$$
u_{i}^{r}=\alpha_{i e}^{r} F_{\mathrm{e}}-\sum_{j} \alpha_{i j}^{r} F_{j}
$$

where $\alpha_{i e}^{r}$ is the transfer receptance of the free rail, giving the response at the connection point $i$ due to a unit force at the excitation point; $\alpha_{i j}^{r}$ is the transfer receptance giving the response on the rail at the connection point $i$ due to a unit force acting at the point $j$.

The relative displacement of the springs connecting the rail and the sleepers is given by

$$
u_{i}^{r}-u_{i}^{s}=\sum_{j} \alpha_{i j}^{p} F_{j}
$$

where $u_{i}^{s}$ is the displacement of the sleepers at the point $i ; \alpha_{i j}^{p}$ is the receptance of the spring connection giving the relative displacement at the point $i$ due to the force acting at the attachment point $j ; F_{j}$ is the interaction force at point $j$. In practice $\alpha_{i j}^{p}=0$ for $i \neq j$.

For the sleepers, the displacement at the connection points is given by

$$
u_{i}^{s}=\sum_{j} \alpha_{i j}^{s} \mathrm{~F}_{j}
$$

For the connection points on different sleepers, which are assumed to be uncoupled, $\alpha_{i j}{ }^{s}=0$, but multiple connection points on one sleeper are allowed in which case it would be non-zero. Considering all the connection points, the equations of motion can be written in matrix form for the three structures

$$
\begin{aligned}
& \mathbf{u}_{r}=\boldsymbol{\alpha}_{e}^{r} F_{e}-\boldsymbol{\alpha}^{r} \mathbf{F} \\
& \mathbf{u}_{r}-\mathbf{u}_{s}=\boldsymbol{\alpha}^{p} \mathbf{F} \\
& \mathbf{u}_{s}=\boldsymbol{\alpha}^{s} \mathbf{F}
\end{aligned}
$$

where $\mathbf{u}_{\mathrm{r}}$ are the displacements on the rail foot at the positions of every spring, while $\mathbf{u}_{\mathrm{s}}$ are the displacements on the top surface of the sleepers at the corresponding points. $\boldsymbol{\alpha}^{r}, \boldsymbol{\alpha}^{p}$ and $\boldsymbol{\alpha}^{s}$ are matrices of the receptances at every connection point of the rail, rail pad and the sleeper respectively due to the force at the spring positions. $\boldsymbol{\alpha}_{e}^{r}$ is the vector of receptances of the rail at the connection points due to the external force $F_{\mathrm{e}}$.

Adding Eqs. (5) and (6) gives 


$$
\mathbf{u}_{r}=\boldsymbol{\alpha}^{p} \mathbf{F}+\boldsymbol{\alpha}^{s} \mathbf{F}
$$

Substituting Eq. (7) into Eq. (4) and rearranging gives

$$
\left(\mathbf{I}+\boldsymbol{\alpha}^{r}\left(\boldsymbol{\alpha}^{p}+\boldsymbol{\alpha}^{s}\right)^{-1}\right) \mathbf{u}_{r}=\boldsymbol{\alpha}_{e}^{r} F_{e}
$$

where $\mathbf{I}$ is the unit matrix. This allows $\mathbf{u}_{r}$ to be obtained as

$$
\mathbf{u}_{r}=\left(\mathbf{I}+\boldsymbol{\alpha}^{r}\left(\boldsymbol{\alpha}^{p}+\boldsymbol{\alpha}^{s}\right)^{-1}\right)^{-1} \boldsymbol{\alpha}_{e}^{r} F_{e}
$$

The displacement at an arbitrary point $k$ on the rail can finally be calculated as

$$
\mathrm{u}_{k}^{r}=\alpha_{k e}^{r} F_{\mathrm{e}}-\boldsymbol{\alpha}_{k}^{r \mathrm{~T}} \mathbf{F}
$$

where $\boldsymbol{\alpha}_{k}^{r}$ is the vector of receptances giving the response at point $k$ on the rail to a unit force at each spring location on the rail foot; $\alpha_{k e}^{r}$ is the transfer receptance from the external force $F_{\mathrm{e}}$ to the response point $k$. Note that the sleeper spacing is not specified in the above formulation; this implies that the coupled track system could have discrete supports with arbitrary spacing.

\subsection{5D FE model of the rail}

To represent an infinite free rail, a 2.5D FE model is used. This approach is described briefly here; more details can be found in [23]. The structure is assumed to be invariant in the $x$ direction; its cross-section is discretized in the $y-z$ plane by using the conventional 2D finite element method with special elements. The equation of motion for harmonic motion of this structure at circular frequency $\omega$ can be written as

$$
\left[\mathbf{K}_{2} \frac{\partial^{2}}{\partial x^{2}}+\mathbf{K}_{1} \frac{\partial}{\partial x}+\mathbf{K}_{0}-\omega^{2} \mathbf{M}\right] \hat{\mathbf{U}}(x)-\hat{\mathbf{F}}(x)=\mathbf{0}
$$

where $\mathbf{K}_{2}, \mathbf{K}_{1}$ and $\mathbf{K}_{0}$ are stiffness matrices and $\mathbf{M}$ is the mass matrix. The matrices $\mathbf{K}_{2}$ and $\mathbf{K}_{1}$ are particular to the $2.5 \mathrm{D}$ approach. $\hat{\mathbf{U}}(x)$ and $\hat{\mathbf{F}}(x)$ are the displacements and external forces at the nodal degrees of freedom as functions of $x$. In order to obtain the equation of motion in the wavenumber domain, a Fourier transform is implemented with respect to the $x$ coordinate.

$$
\tilde{\mathbf{U}}(\kappa)=\int_{-\infty}^{\infty} \hat{\mathbf{U}}(x) e^{i \kappa x} \mathrm{~d} x
$$




$$
\hat{\mathbf{U}}(x)=\frac{1}{2 \pi} \int_{-\infty}^{\infty} \tilde{\mathbf{U}}(\kappa) e^{-i \kappa x} \mathrm{~d} \kappa
$$

where $K$ is the wavenumber in the $x$-direction and tilde denotes the Fourier transformed properties in the wavenumber domain. Eq. (11) can then be written as

$$
\left[\mathbf{K}_{2}(-i \kappa)^{2}+\mathbf{K}_{1}(-i \kappa)+\mathbf{K}_{0}-\omega^{2} \mathbf{M}\right] \tilde{\mathbf{U}}=\tilde{\mathbf{F}}
$$

If $\tilde{\mathbf{F}}=\mathbf{0}$ in Eq. (14), the equation represents a double eigenvalue problem. This can be viewed as a linear eigenvalue problem in squared frequency $\omega^{2}$ for a given wavenumber $\kappa$, or equivalently as a quadratic eigenvalue problem in wavenumber $\kappa$ for a given frequency $\omega$. The latter gives complex-valued wavenumbers $\kappa_{n}$ and the corresponding right and left eigenvectors (denoted by $\tilde{\mathbf{U}}_{n R}$ and $\tilde{\mathbf{U}}_{n L}$ respectively) for each frequency.

To obtain the response due to a point force applied at $x=0$, the integral in Eq. (13) can be evaluated by a contour integration [41]. For $x \geq 0$, the solution to the integral is given by the sum of the residues of the poles lying in the lower half plane, $\operatorname{Im}\left(\kappa_{n}\right)<0$. The poles are the eigenvalues, $\kappa_{n}$ determined from Eq. (14). The solution for $\hat{\mathbf{U}}$, the displacements of the structure along the $x$ direction, is written as [22]

$$
\hat{\mathbf{U}}=i \sum_{n} \frac{\tilde{\mathbf{U}}_{n L} \tilde{\mathbf{F}}_{0}}{\tilde{\mathbf{U}}_{n L} \mathbf{D}^{\prime}\left(\kappa_{n}\right) \tilde{\mathbf{U}}_{n R}} \tilde{\mathbf{U}}_{n R} \mathrm{e}^{-i \kappa_{n} x} \quad \text { for } x \geq 0
$$

where

$$
\begin{aligned}
\mathbf{D}^{\prime}\left(\kappa_{n}\right) & =\frac{\partial}{\partial \kappa}\left[\mathbf{K}_{2}(-i \kappa)^{2}+\mathbf{K}_{1}(-i \kappa)+\mathbf{K}_{0}-\omega^{2} \mathbf{M}\right]_{\kappa=\kappa_{n}} \\
& =-2 \kappa_{n} \mathbf{K}_{2}-i \mathbf{K}_{1}
\end{aligned}
$$

For the series in Eq. (15), $n$ is truncated so that the number of waves included is sufficient to calculate the displacement of the rail. The solution for $x<0$ is symmetric with that for $x \geq 0$. By setting $F_{0}=1$ at a single node of the cross-section, either on the rail head or the rail foot, this model can be used to determine the receptances $\boldsymbol{\alpha}^{r}$ and $\boldsymbol{\alpha}_{e}^{r}$ for the rail as required for the receptance-coupling method.

\subsection{Rail pad model}

The rail pad connects the rail to the sleeper dynamically and therefore plays an important role in the dynamic response of the track. Although many authors use a viscous damping model [4], consisting of a spring and dashpot in series, measurements of rail pad dynamic stiffness 
have shown the behaviour to be better approximated by a constant loss factor model $[1,42,43]$. For example, measurements presented in [43] for natural rubber pads showed that the stiffness magnitude was mildly frequency dependent but the phase angle of the measured stiffness was approximately constant with frequency. A model with a constant loss factor can cause some difficulties for time-domain modelling, where causality is only satisfied if the magnitude is frequency dependent. However, for frequency-domain models the use of constant values of both stiffness and loss factor lead to a satisfactory approximation of the physical properties whereas in a viscous damping model the losses are too small at low frequencies and too large at high frequencies [1]. The present model uses a hysteretic damping model with constant stiffness and loss factor, although it would also be possible to introduce frequency dependence.

\subsection{Sleeper model with ballast support}

Although a numerical model could also be used for the sleepers, they are considered here as uniform flexible beams supported on a damped elastic layer to represent the ballast. The modelling approach used for the sleeper is based on that presented by Thompson [1], where the receptance of the sleeper for the vertical direction is obtained from a wave approach. The model used here is an extended version [44], which includes the axial motion as well as the vertical bending. Coupling between axial and vertical motions of the sleeper occurs due to the fact that the ballast springs are assumed to act at the bottom of the sleeper [44].

The sleeper is represented as a finite uniform Timoshenko beam with length $L$, and is assumed to be supported on a continuous visco-elastic foundation (representing the ballast), as shown in Figure 2. Transformations are applied to determine the receptance matrix for positions at the top surface of the sleeper. This model is then coupled to the rail through the rail pads using the method described in Section 2.1.

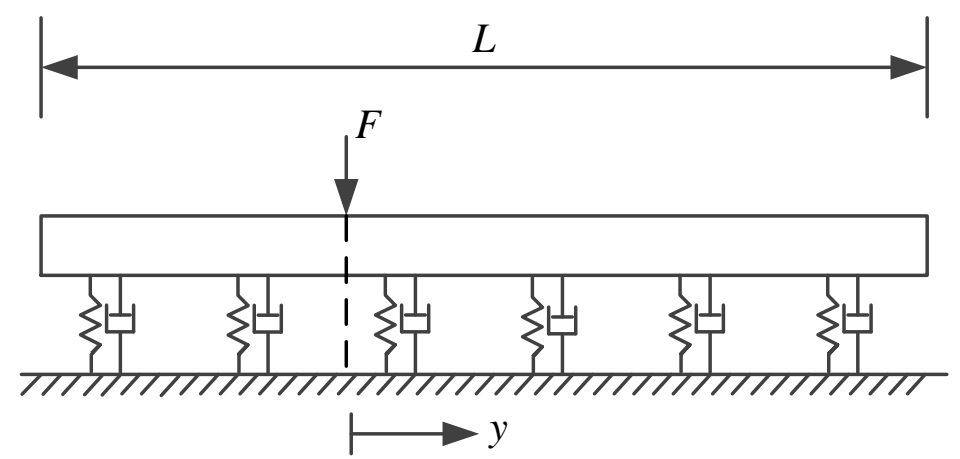

Figure 2 Sleeper represented as a finite Timoshenko beam on an elastic foundation (side view) 
To illustrate the results of the flexible sleeper model, and to obtain the necessary material properties, a series of mobility measurements (mobility is the velocity per unit force) have been conducted by using an impact hammer on a pre-stressed type G44 concrete sleeper in the laboratory [44]. The sleeper was supported on soft rubber mounts under each rail seat giving a bounce mode natural frequency of $20 \mathrm{~Hz}$. The driving point mobility of the sleeper was measured when it was excited vertically at one end. The measured mobility magnitude and phase are shown in Figure 3, and compared with the corresponding predictions obtained by using the flexible sleeper model. Good agreement can be seen between them apart from the first bending mode at around $120 \mathrm{~Hz}$ which is most affected by the assumption of a uniform cross-section [32]. The sleeper properties used are listed in Table 1. The equivalent sleeper density is derived from the total mass of $300 \mathrm{~kg}$ and the assumed uniform crosssection of the model.
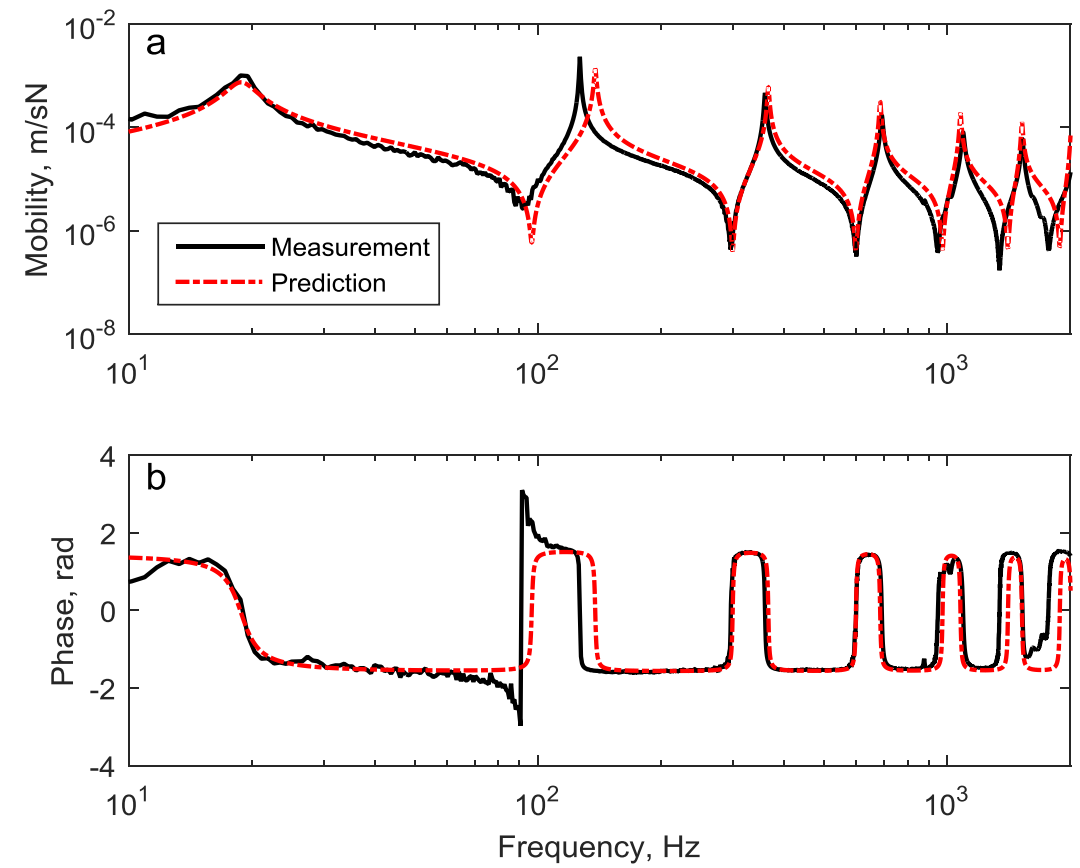

Figure 3 Point mobility of concrete monobloc sleeper for vertical excitation at one end on the centreline of the sleeper upper surface [44]

A visco-elastic model is used for the ballast. In Figure 4 measurement data from $[1,45]$ for the magnitude of the dynamic stiffness are compared with the results of this model for a stiffness of $50 \mathrm{MN} / \mathrm{m}^{2}$ and a damping of $120 \mathrm{kNs} / \mathrm{m}^{2}$. As the stiffness and damping of ballast vary considerably from one location to another, they will be chosen in the following section according to the site measurements. 


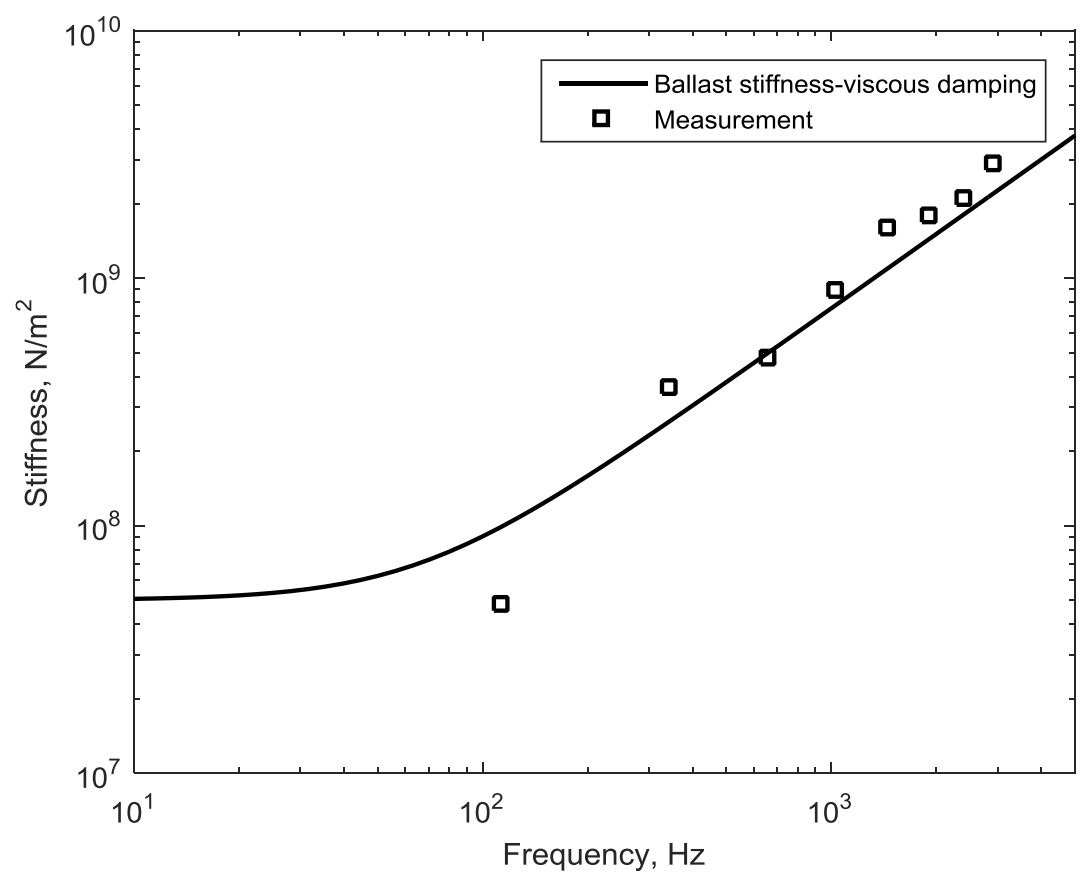

Figure 4 Comparison of the ballast dynamic stiffness magnitude with measurements [45]

Using the sleeper properties in Table 1, the point mobility of the sleeper at the rail seat when located in ballast is presented in Figure 5. The stiffness and damping values of the ballast per unit length along the sleeper is taken as the same as those used in Figure 4. The result is compared with its counterpart from a mass model of the sleeper in which the sleeper mass is taken as $150 \mathrm{~kg}$ for one rail. In this case the ballast stiffness and damping values are taken as 62.5 MN/m and $150 \mathrm{kNs} / \mathrm{m}$ (i.e. corresponding to a length of $1.25 \mathrm{~m}$ ).

Many resonances can be seen in the result from the flexible beam model. The first peak at around $100 \mathrm{~Hz}$ is the resonance of the sleeper mass on the stiffness of the ballast foundation and is the same in both models. There are a number of bending resonances of the beam above this frequency, as seen already in Figure 3. The ballast support causes their natural frequencies to increase compared with the free sleeper, and their damping is also much greater. 

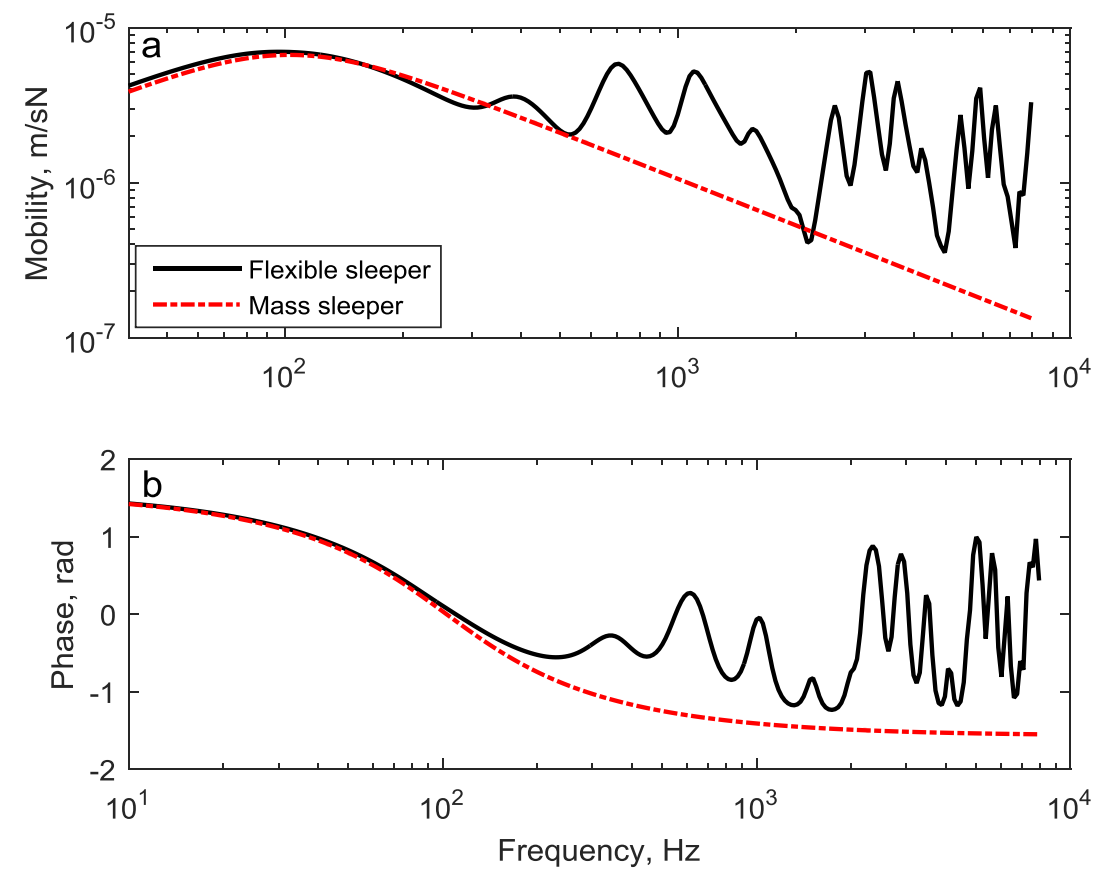

Figure 5 Predicted vertical point mobility of the sleeper in ballast excited at the rail seat

Table 1 Properties used for the monobloc sleeper

\begin{tabular}{|l|l|}
\hline Young's modulus & $57 \mathrm{GPa}$ \\
\hline Shear modulus & $23.8 \mathrm{GPa}$ \\
\hline Density & $2648 \mathrm{~kg} / \mathrm{m}^{3}$ \\
\hline Length & $2.5 \mathrm{~m}$ \\
\hline Poisson's ratio & 0.2 \\
\hline Damping loss factor & 0.0083 \\
\hline Equivalent height & $0.185 \mathrm{~m}$ \\
\hline Equivalent breadth & $0.245 \mathrm{~m}$ \\
\hline Second moment of area for vertical bending & $1.27 \times 10^{-4} \mathrm{~m}^{4}$ \\
\hline Vertical shear coefficient & 0.83 \\
\hline Vertical shear centre eccentricity & 0 \\
\hline
\end{tabular}

\section{Validation of the model}

\subsection{The coupled track model}

The receptance coupling method described in Section 2 is applied to a discretely supported railway track, as illustrated in Figure 6. The infinite rail is coupled to a finite number of sleepers, as shown in Figure 6(a). The infinite free rail is modelled by using the 2.5D FE 
method with a distributed elastic support for the rail pad and a flexible sleeper model including the ballast beneath it, as shown in Figure 6(b). For the coupling of the 2.5D FE rail and the flexible sleepers, the top surfaces of the monobloc sleepers are connected to the rail via a series of springs distributed across the bottom of the rail foot.

(a)

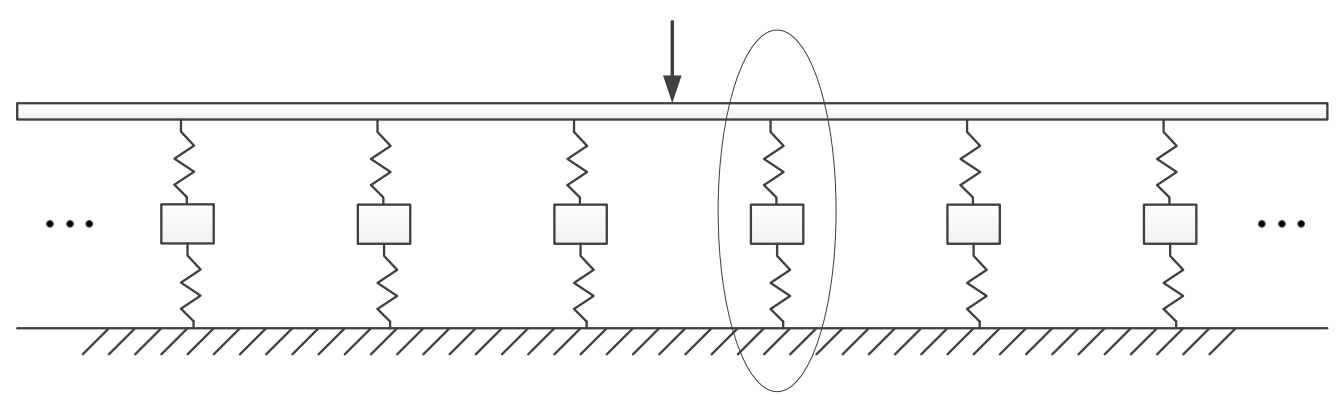

(b)

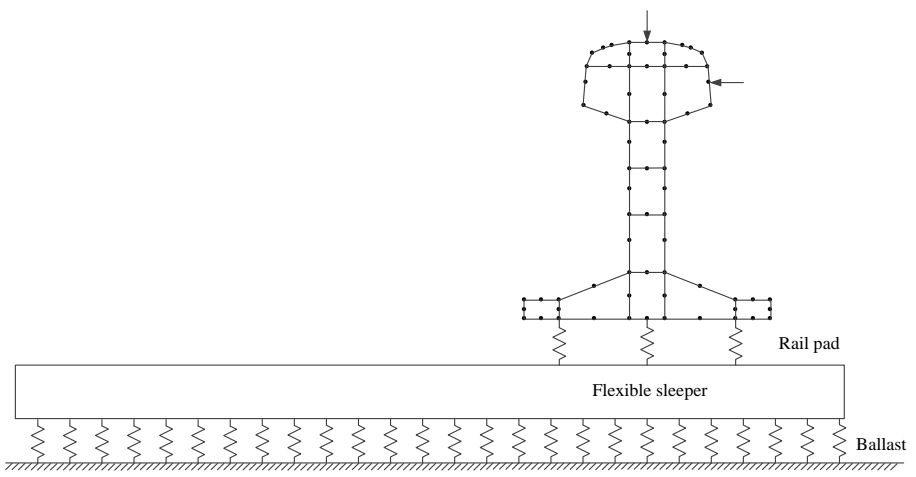

Figure 6 Model of a discretely supported track. (a) Rail on discrete supports in the longitudinal direction; (b) 2.5D FE mesh of the rail and the springs distributed across the rail foot

The 2.5D FE model of the free rail is first used to obtain the receptances of the free rail, see Section 2.2. The response to both vertical and lateral forces on the rail head is considered at the positions shown in Figure 6(b). For the vertical direction the position is at the centre of the rail head and for the lateral direction it is on the side of the rail head. Each rail pad is discretized initially by a single line of three springs across the rail foot (other configurations are compared in Section 4.3). The stiffness of each spring is determined according to the transverse length of the rail foot to which it is attached [40]. So, for example, for the three springs shown in Figure 6(b), the stiffnesses are 0.3215, 0.357 and 0.3215 multiplied by the rail pad stiffness. In order to ensure that the waves generated are sufficiently attenuated at the ends of the finite supported region, 131 rail supports are used in the longitudinal direction to represent the infinite supported rail. The rail vibration is found to decay by at least $10 \mathrm{~dB}$ over this length at all frequencies which is more than sufficient to avoid any effect of the 
wave reflections from the ends. As well as the point receptances, the transfer receptances of the track are calculated for various response points and used to determine the track decay rates in accordance with the EN 15461 procedure [46]. For this, the excitation is applied at mid-span.

Calculations are made for parameters corresponding to two ballasted tracks for which measurements have been obtained and the results are compared with the measurements. These tracks are from an operational site at Fishbourne, Sussex, UK. Both tracks consist of 56El rails and monobloc concrete sleepers. One track, denoted track A, had not been renewed whereas the other, track $\mathrm{B}$, had recently been renewed, with a complete replacement of ballast, sleepers, pads and rails; the sleeper spacing was also changed. The most important difference between these two tracks is the rail pad, the renewed track having a much softer rail pad and consequently lower decay rates. A PCB 086C03 hammer and an accelerometer of type B\&K 4514-001 (100 mV/g) were used in the measurement. The mobilities were obtained using an average of 10 impacts in each case. The coherence was always above 0.8 above $50 \mathrm{~Hz}$ and close to 1 for most frequencies. The decay rates of both tracks were determined from transfer mobilities measured at different distances along the track, in accordance with EN 15461 [46]. Again, the coherence was above 0.8 apart from isolated frequencies for all transfer mobilities that have been used in determining the decay rates. Note that only transfer mobilities above $-15 \mathrm{~dB}$ relative to the point mobility are included in the analysis.

To derive the parameters of the rail pads and ballast, a basic curving fitting procedure is carried out by matching the decay rate predicted by the coupled track model with the corresponding measured decay rates. The various track properties, including the pad and ballast stiffness and damping, are determined for both tracks, and are tabulated in Table 2 . As can be seen, the vertical ballast stiffness of track B is found to be lower than that of track A. A possible reason for this difference is that the old ballast had become compacted whereas the new track was laid with $250 \mathrm{~mm}$ of new ballast, $50 \mathrm{~mm}$ of sand blanket and geocomposite [47]. The sleeper properties from Table 1 are used for both tracks.

Table 2 Parameters used for the ballasted tracks in the predictions

\begin{tabular}{|l|l|l|}
\hline Rail parameters & Track A & Track B \\
\hline Rail cross section & $56 \mathrm{E} 1$ & $56 \mathrm{E} 1$ \\
\hline
\end{tabular}




\begin{tabular}{|c|c|c|}
\hline Rail vertical bending stiffness & $4.86 \mathrm{MNm}^{2}$ & $4.86 \mathrm{MNm}^{2}$ \\
\hline Rail lateral bending stiffness & $0.88 \mathrm{MNm}^{2}$ & $0.88 \mathrm{MNm}^{2}$ \\
\hline Rail vertical loss factor & 0.01 & 0.015 \\
\hline Rail lateral loss factor & 0.015 & 0.01 \\
\hline Rail fastener & Pandrol e-clip & Pandrol Fastclip \\
\hline \multicolumn{3}{|l|}{ Rail pad parameters } \\
\hline Pad vertical stiffness & $400 \mathrm{MN} / \mathrm{m}$ & $90 \mathrm{MN} / \mathrm{m}$ \\
\hline Pad lateral stiffness & $30 \mathrm{MN} / \mathrm{m}$ & $45 \mathrm{MN} / \mathrm{m}$ \\
\hline Pad vertical loss factor & 0.25 & 0.3 \\
\hline Pad lateral loss factor & 0.15 & 0.1 \\
\hline \multicolumn{3}{|c|}{ Sleeper parameters (see Table 1) } \\
\hline Sleeper spacing & $0.78 \mathrm{~m}$ & $0.65 \mathrm{~m}$ \\
\hline \multicolumn{3}{|l|}{$\begin{array}{l}\text { Ballast parameters (per unit } \\
\text { length along the sleeper) }\end{array}$} \\
\hline Ballast vertical stiffness & $104 \mathrm{MN} / \mathrm{m}^{2}$ & $68 \mathrm{MN} / \mathrm{m}^{2}$ \\
\hline Ballast lateral stiffness & $64 \mathrm{MN} / \mathrm{m}^{2}$ & $48 \mathrm{MN} / \mathrm{m}^{2}$ \\
\hline Ballast vertical damping & $38 \mathrm{kNs} / \mathrm{m}^{2}$ & $22 \mathrm{kNs} / \mathrm{m}^{2}$ \\
\hline Ballast lateral damping & $157 \mathrm{kNs} / \mathrm{m}^{2}$ & $38 \mathrm{kNs} / \mathrm{m}^{2}$ \\
\hline
\end{tabular}

The cross-section of a free 56E1 rail is discretized into 8-noded quadrilateral elements in the $y-z$ plane, as presented in Figure 7. Two different mesh densities are compared. The one in Figure 7(a) has 14 elements and 207 degrees of freedom, whereas the one in Figure 7(b) has 40 elements and 507 degrees of freedom. The dynamic response of track A is predicted by using the two meshes in the coupled track model with 30 eigenvalues (waves) used in the residue method in Eq. (16); the corresponding results are compared in Figure 8. As can be seen, these two meshes give almost identical results, with only slight differences at high frequency. Thus, the first mesh will be used for the results in the rest of this paper. 

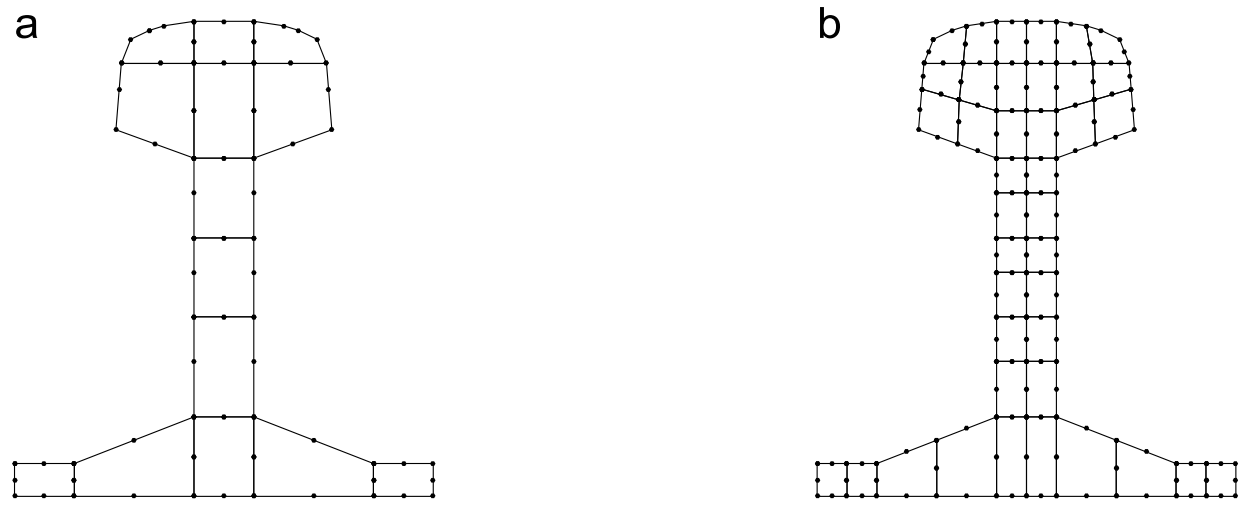

Figure 7 Cross-sectional model for a free rail. (a) Mesh 1; (b) Mesh 2

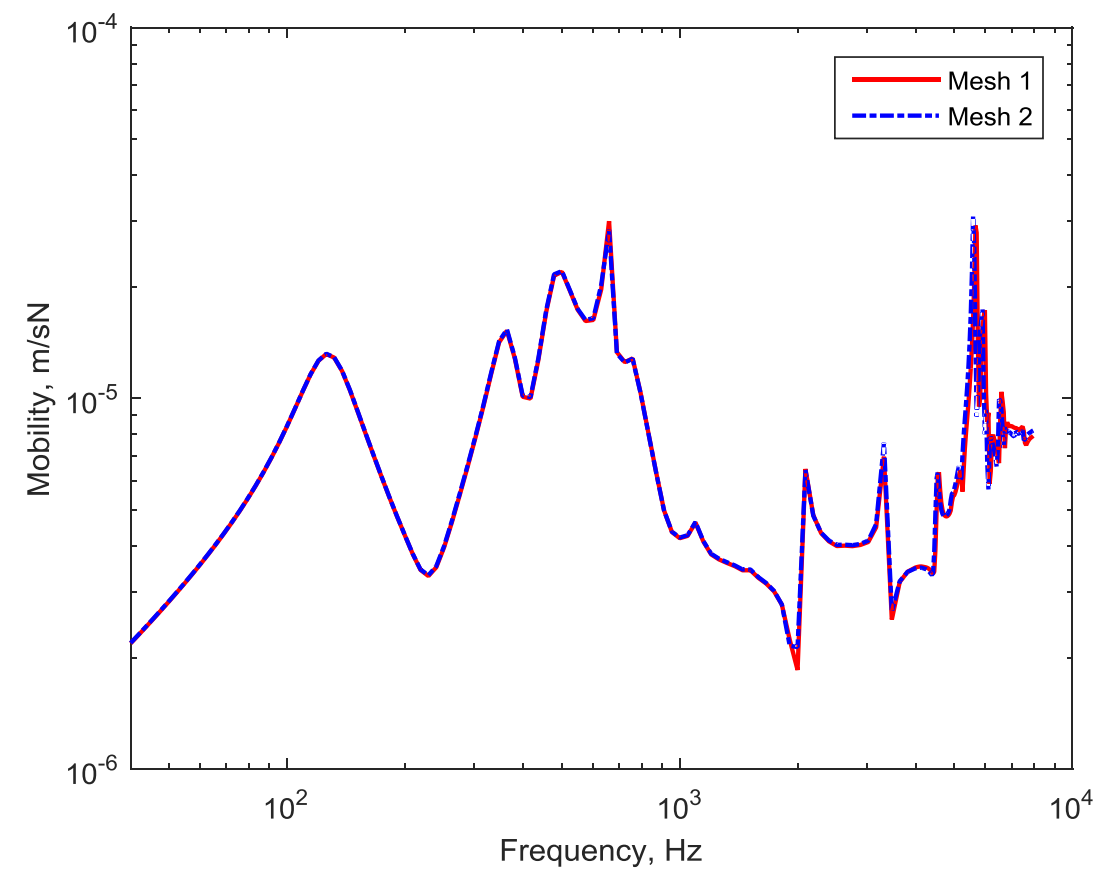

Figure 8 Comparison of the magnitude of the vertical point mobility found by using two different meshes for track A

\subsection{Track A: stiff rail pads}

Figure 9 compares the driving point mobilities of track A, with vertical rail pad stiffness 400 $\mathrm{MN} / \mathrm{m}$, for the vertical excitation mid-way between sleepers and directly above a sleeper. The results are predicted by using the parameters given in Table 2 for the frequency range from 40 to $8000 \mathrm{~Hz}$, with a logarithmic spacing and 50 points per decade. As can be seen, there are large differences between the results for the two excitation points, especially in the frequency range between $200 \mathrm{~Hz}$ and $2000 \mathrm{~Hz}$. For the excitation at mid-span between sleepers, three 
pronounced peaks can be seen in the mobility, at around $130 \mathrm{~Hz}, 500 \mathrm{~Hz}$ and $700 \mathrm{~Hz}$. The first peak corresponds to the resonance of the mass of the rail and the sleeper on the vertical ballast stiffness, whereas the second one represents the resonance frequency of the rail mass on the stiffness of the rail pad [1]. The smaller peak at $350 \mathrm{~Hz}$ is the second bending mode of the sleeper (see Figure 5). The third peak at $700 \mathrm{~Hz}$ is the vertical 'pinned-pinned' frequency; just above this frequency the mobility above the sleeper has a dip.

The predictions of the point mobilities and the track decay rate are compared with the corresponding measured results in Figure 10 and Figure 11 for vertical excitation at mid-span. Quite good agreement can be seen between the predicted and measured point mobilities, despite the fact that the pad and ballast stiffnesses have been chosen to give a best fit to the decay rates rather than the mobilities. The track decay rate, however, is underestimated between $800 \mathrm{~Hz}$ and $4 \mathrm{kHz}$, as shown in Figure 11. This underestimation suggests a higher pad stiffness might be more appropriate above $1 \mathrm{kHz}$ in the prediction.
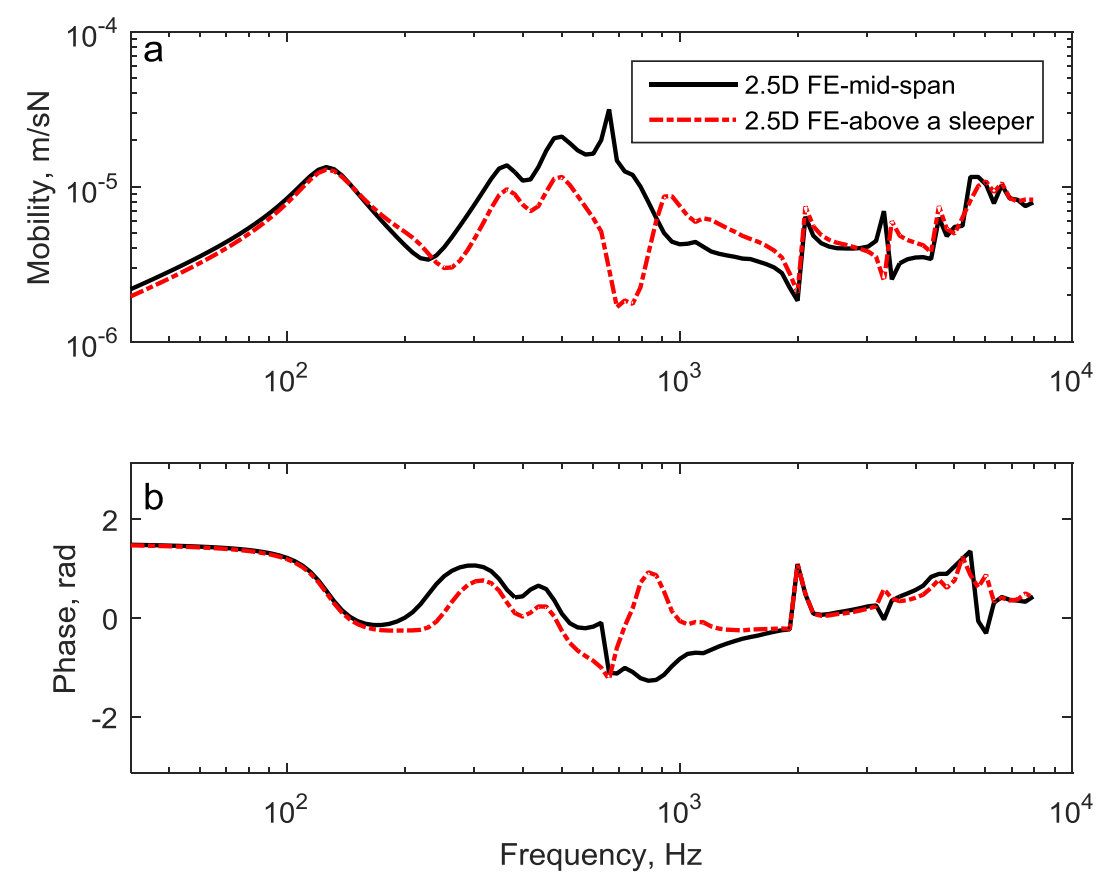

Figure 9 The vertical point mobility of track A predicted by the 2.5D FE track model 

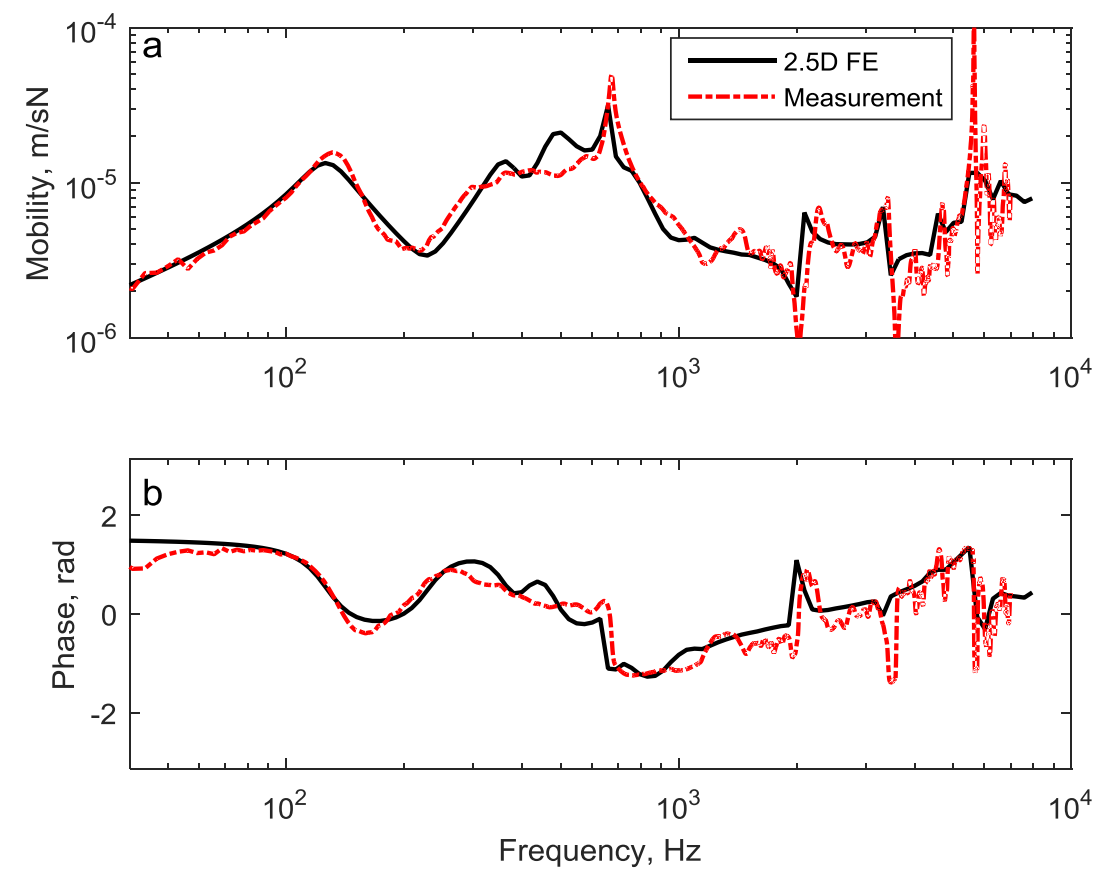

Figure 10 Comparison of the predicted vertical point mobility of track A with the measurement for the excitation at mid-span

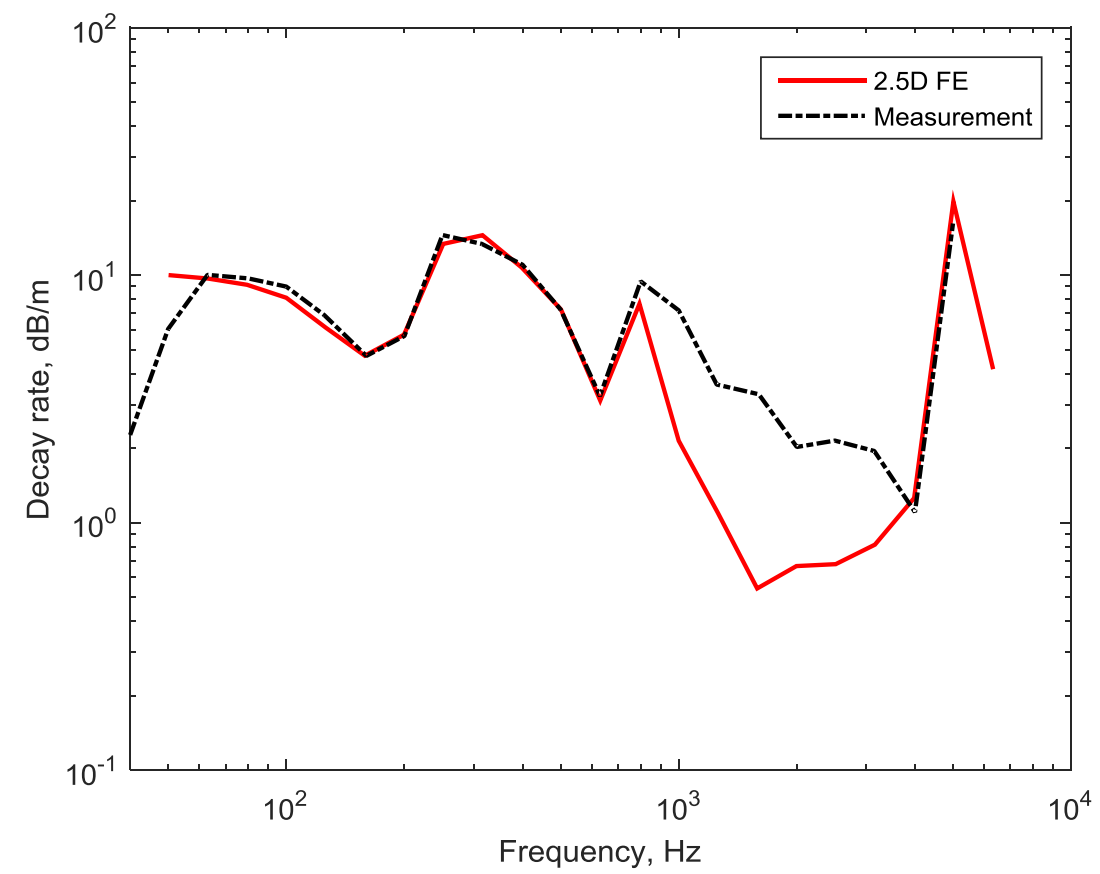

Figure 11 Comparison of the predicted vertical decay rate of track A with the measurement

The driving point mobilities in the lateral direction are shown in Figure 12. This compares the measured results at mid-span with the corresponding results from the model. The lateral force is applied at the middle of the rail head, as shown in Figure 6(b). Good agreement can be seen between the measured and predicted mobility in terms of both the magnitude and phase. 
Distinct peaks can be observed in the results at $110 \mathrm{~Hz}$, corresponding to the resonance of the combined system of the rail and sleeper on the lateral ballast stiffness, at $300 \mathrm{~Hz}$ which is the lateral 'pinned-pinned' resonance and at $600 \mathrm{~Hz}$ which is the torsional 'pinned-pinned' resonance [44]. At these two frequencies the mobility above a sleeper has a dip. The predicted track decay rate for lateral excitation is also compared with the measurement data in Figure 13. As can be seen, the overall trend of the numerical predictions is similar to that of the measurements although there are some differences between them. In terms of $10 \log _{10}$ (decay rate), which is relevant to noise radiation, the average error is $-0.6 \mathrm{~dB}$, while the standard deviation is $1.7 \mathrm{~dB}$.
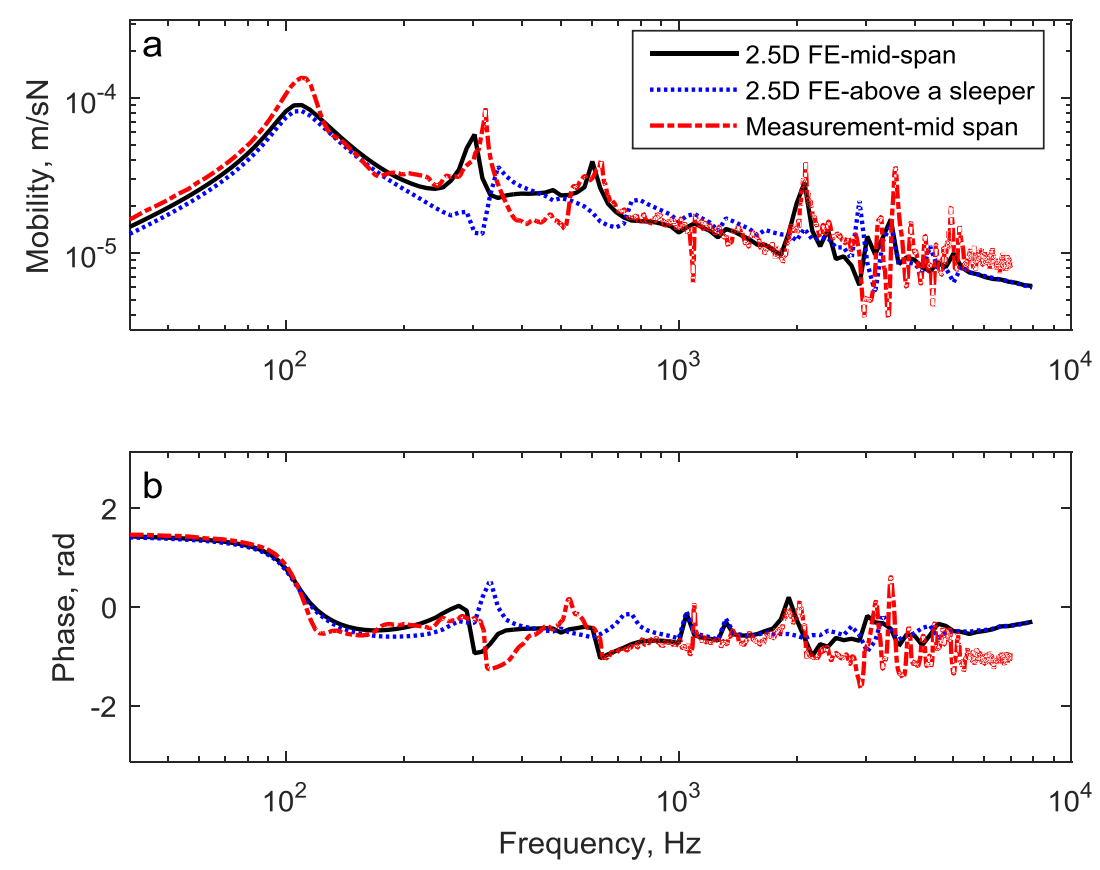

Figure 12 Comparison of the measured point mobility of track A with the prediction for lateral excitation 


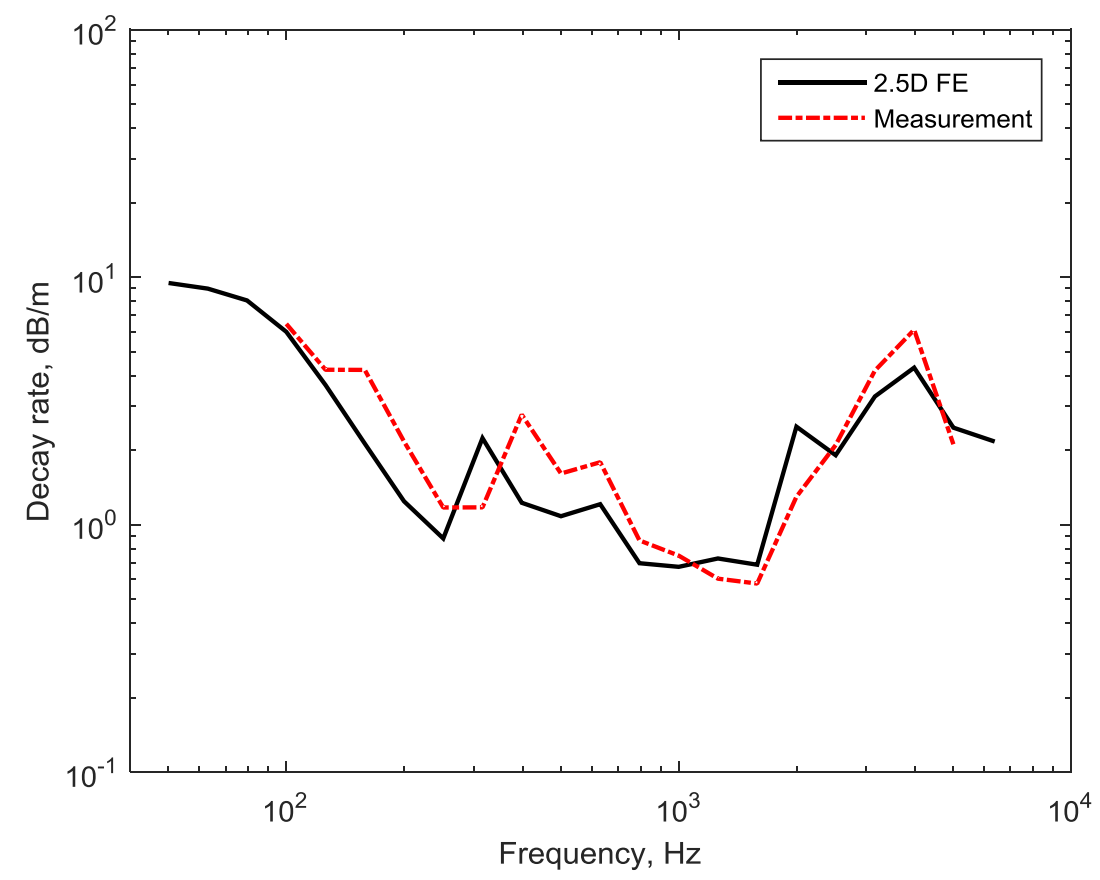

Figure 13 Comparison of the predictions and the measurements of the lateral track decay rate of track A

\subsection{Track B: soft rail pads}

In the same fashion, the driving point mobility and the decay rate of Track B with the softer rail pad (vertical stiffness $90 \mathrm{MN} / \mathrm{m}$ ) have been predicted for both vertical and lateral excitation by using the corresponding parameters in Table 2. The predicted point mobilities are compared with the corresponding measured results in Figure 14 for excitation at midspan.Very good agreement can be seen, especially below $2500 \mathrm{~Hz}$. The track decay rates are shown in Figure 15. These show good agreement over the whole frequency range with a slight under-prediction in the region $315-1600 \mathrm{~Hz}$. In terms of $10 \log _{10}$ (decay rate), the average error is $-0.2 \mathrm{~dB}$. Due to the lower pad stiffness, the resonance of the rail mass on the pad stiffness is decreased to approximately $300 \mathrm{~Hz}$ for this track. The pinned-pinned resonance occurs here at about $900 \mathrm{~Hz}$, which is higher than for track A because the sleeper spacing is smaller for track B. Compared with track A, the two peaks seen previously at 300 $\mathrm{Hz}$ and $800 \mathrm{~Hz}$ in the decay rate occur here at about $200 \mathrm{~Hz}$ and $1000 \mathrm{~Hz}$. These again correspond to the anti-resonance at which the sleeper acts as a dynamic absorber to the rail and the 'pinned-pinned' resonance.

Results are also shown in Figure 16 and Figure 17 for the lateral response of track B, when the excitation is at mid-span. Good agreement is again obtained especially below $2500 \mathrm{~Hz}$. 

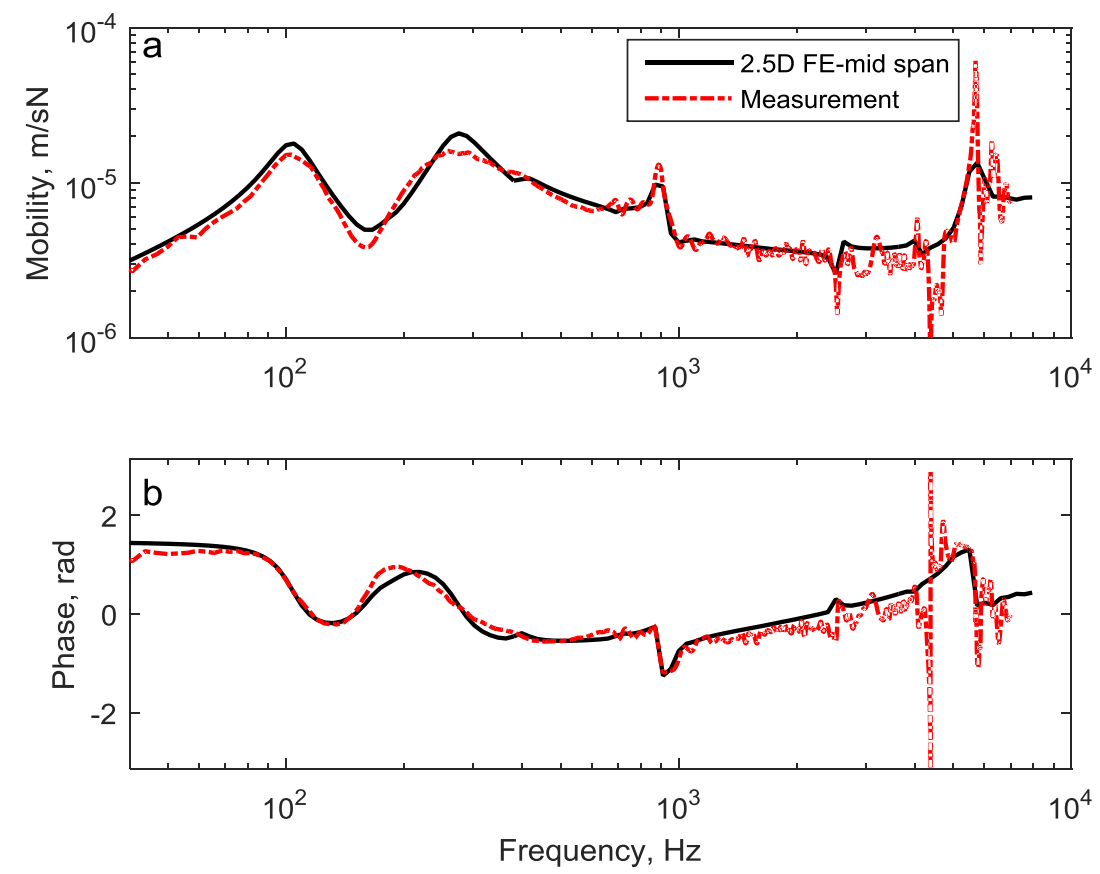

Figure 14 Comparison of the predicted vertical point mobility of track B with the measurement for excitation at mid-span

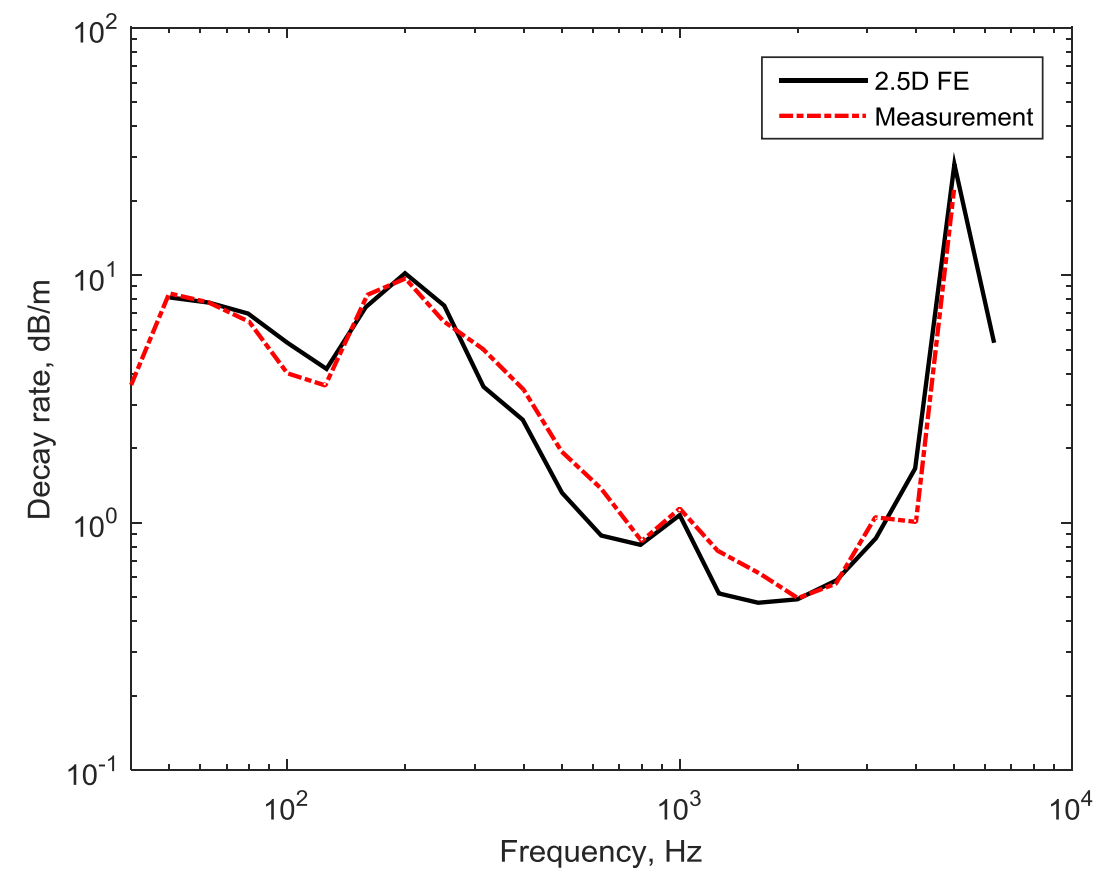

Figure 15 Comparison of the predicted and measured vertical decay rate of track B 

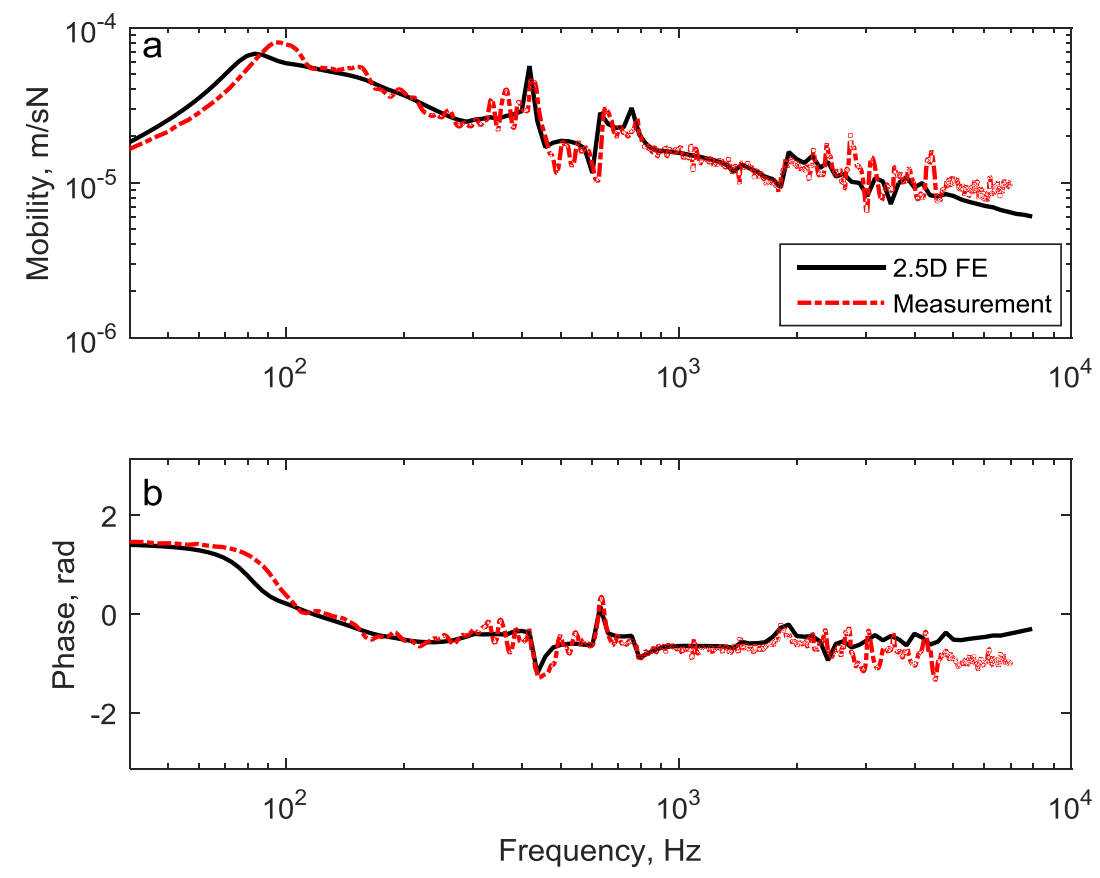

Figure 16 Comparison of the measured point mobility of track B with the prediction for lateral excitation

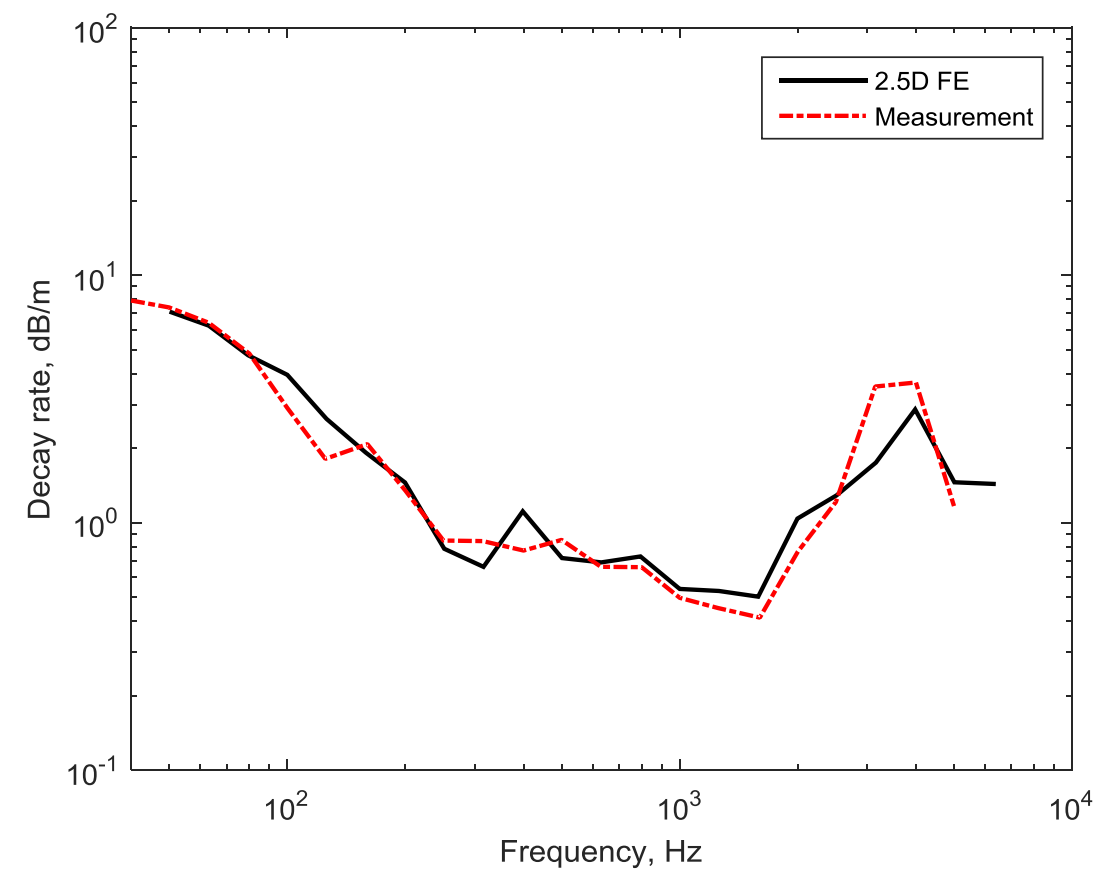

Figure 17 Comparison of the predictions and the measurements of the lateral track decay rate of track B 


\section{Parameter study}

\subsection{Different sleeper models}

For a continuously supported rail, or even a rail with a periodic support, it is common that the sleeper is modelled as a mass without bending stiffness along the rail axis. This conventional mass model is considered here for comparison. The corresponding model is presented in Figure 18, where the rail support with half the mass of a sleeper $(150 \mathrm{~kg})$ is assumed to be connected to the middle of the rail foot by a single spring. The parameters from Table 2 are used in this model to predict the vertical mobilities of both tracks. The ballast support used in the mass model also includes viscous damping. The results are presented in Figure 19 and Figure 20 and are compared with the corresponding predictions obtained with the flexible beam for the sleepers. As can be seen in Figure 19, for the track with stiff rail pads, the two sleeper models show significant differences between 200 and $800 \mathrm{~Hz}$, as can be expected from Figure 5, due to the sleeper modes which are apparent in the rail mobility. Conversely for the track with soft rail pads, the results are similar for the two sleeper models. In this case the flexible behaviour of the sleeper has little influence on the rail vibration because of the presence of the soft rail pad between them.

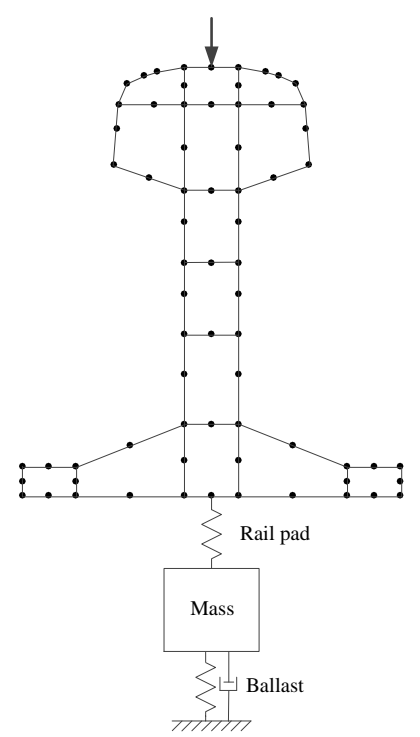

Figure 18 2.5D FE mesh of the rail and single spring-mass-spring system attached to the middle of the rail foot 

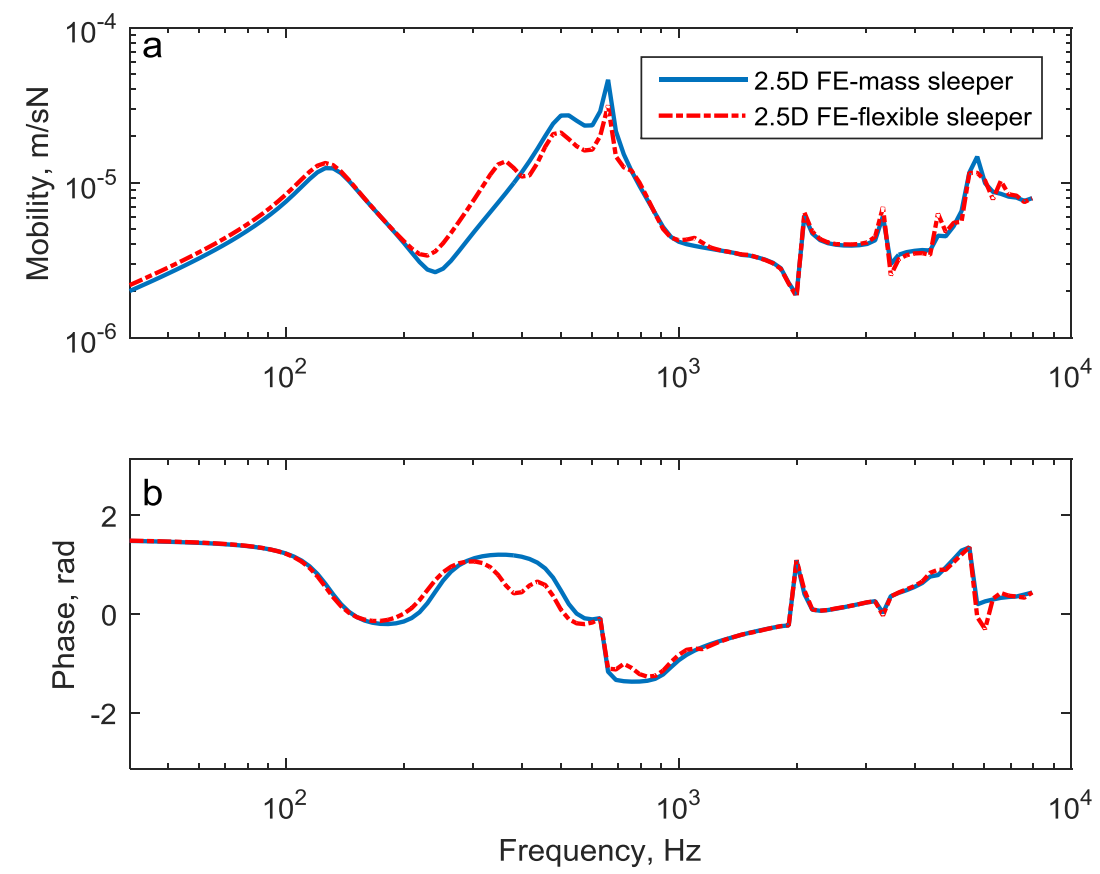

Figure 19 Vertical point mobility of track A by using different sleeper models
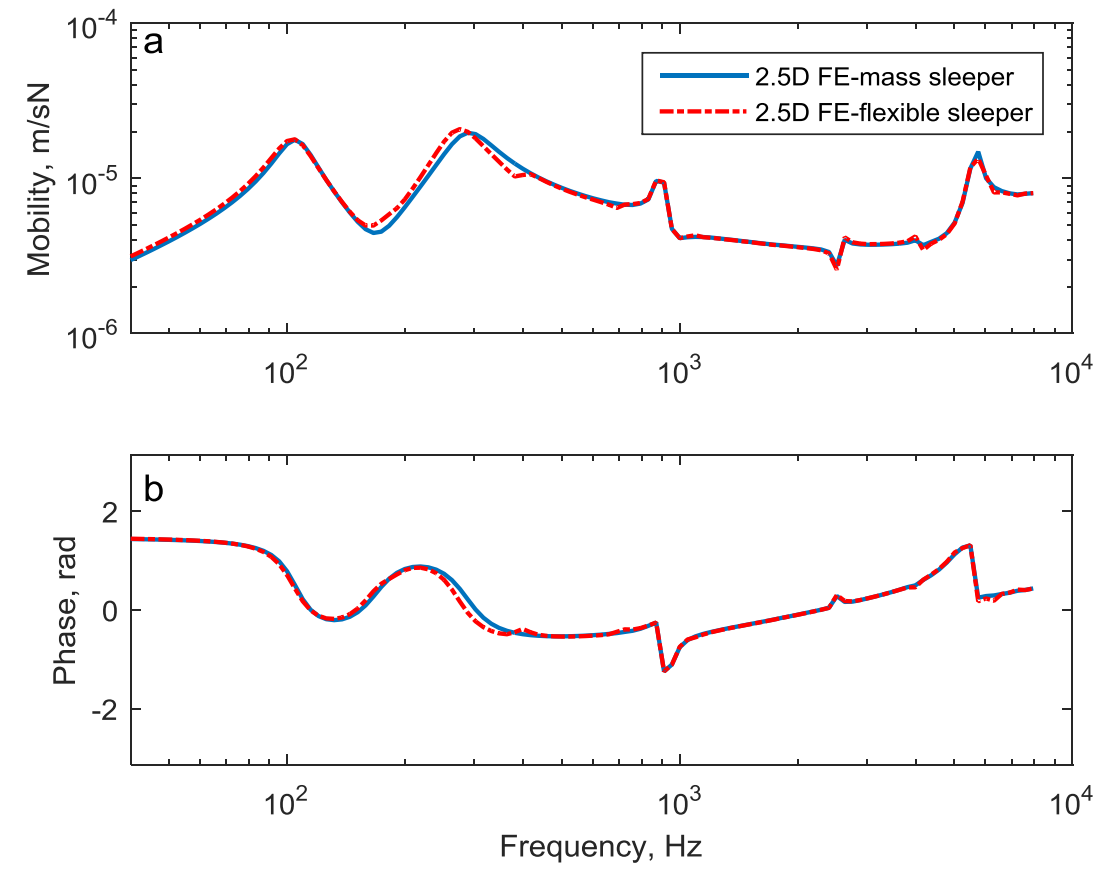

Figure 20 Vertical point mobility of track B by using different sleeper models 


\subsection{Timoshenko beam model for the rail}

The classic Timoshenko beam is commonly used to model the rail. This conventional beam is adopted here, with discrete double layer supports used to represent the sleepers and ballast. The sleeper mass is $150 \mathrm{~kg}$ per support, as in the previous section. The same procedure is used, as described in Section 2.1, to determine the track response.

The mobility of track A for vertical excitation is presented in Figure 21 for the Timoshenko beam with masses representing the sleepers and for the 2.5D FE model with the mass sleeper model. In these results, the force is applied to the mid-span of the sleeper. The viscous damping model is again used for the ballast in these two models. The results from the Timoshenko beam model are very similar to those from the 2.5D FE model for frequencies below $5000 \mathrm{~Hz}$, but at high frequencies the cross-sectional deformation of the rail has a strong influence on the results.

The track decay rates predicted by using the two track models are presented in Figure 22 and also compared with those from the 2.5D FE model with the flexible sleeper. As can be seen, the results from the two models with mass sleeper model are quite similar except at high frequency where the cross-sectional deformation of the rail has a strong effect. The flexible sleeper model has an influence on the track decay rates in the frequency range of $160 \mathrm{~Hz}$ and $800 \mathrm{~Hz}$.

The corresponding decay rates for track B are shown in Figure 23. A high peak in the track decay rate is again seen at $5 \mathrm{kHz}$ for the $2.5 \mathrm{D}$ FE model due to cross-section deformation. The flexible sleeper model has limited influence on the track decay rate for this track due to the soft rail pad. 

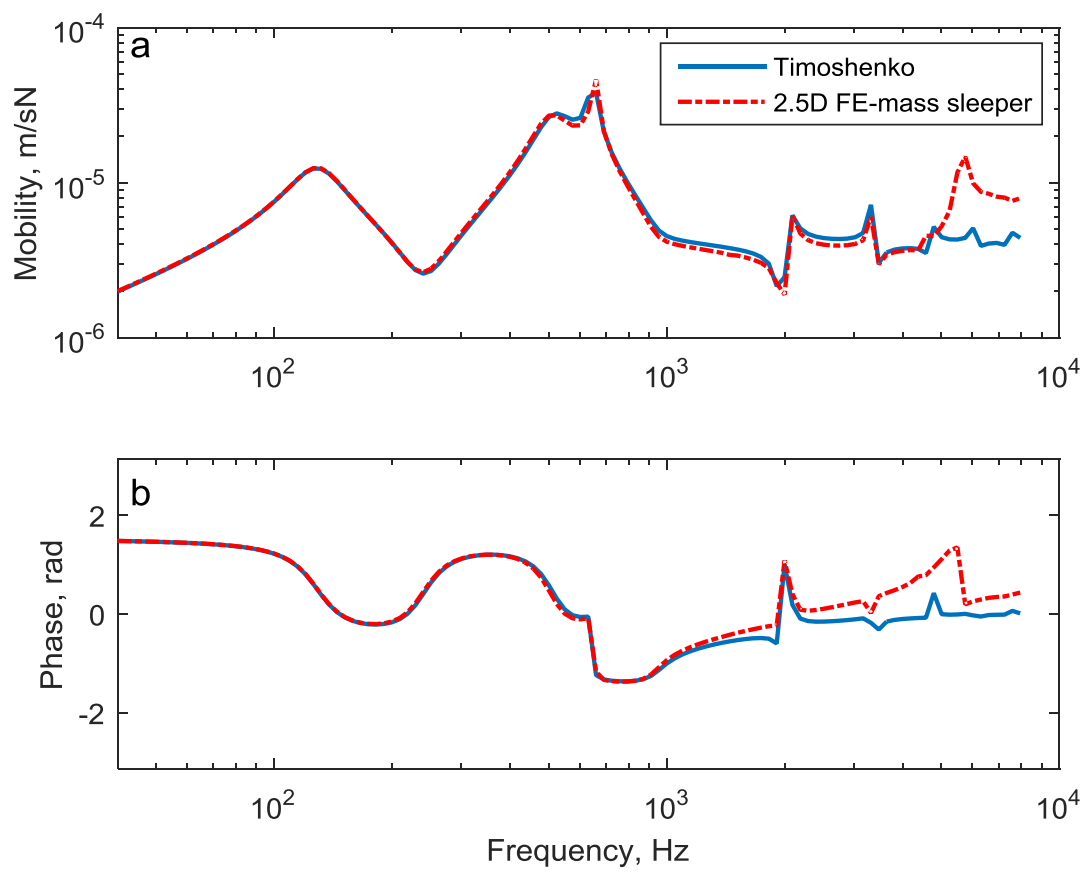

Figure 21 The vertical point mobility of track A predicted by different models

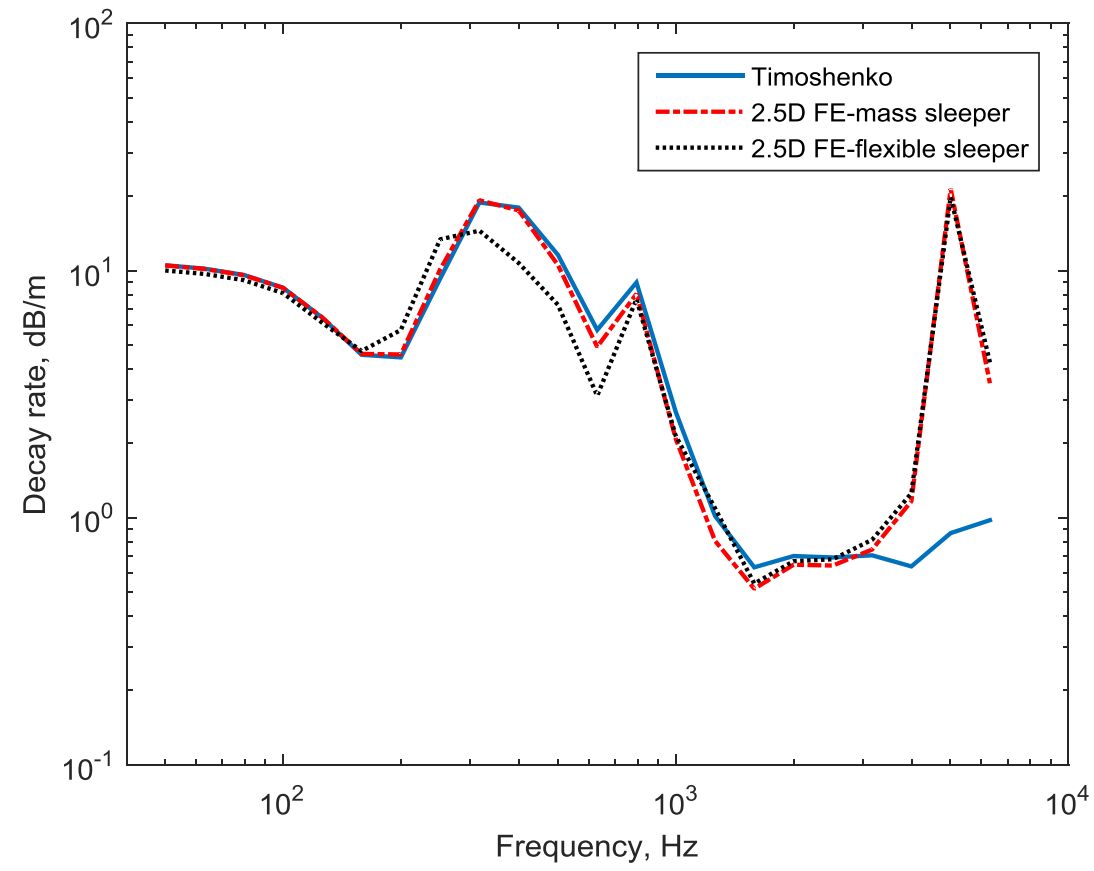

Figure 22 Predictions of the track decay rate of track A by using different models 


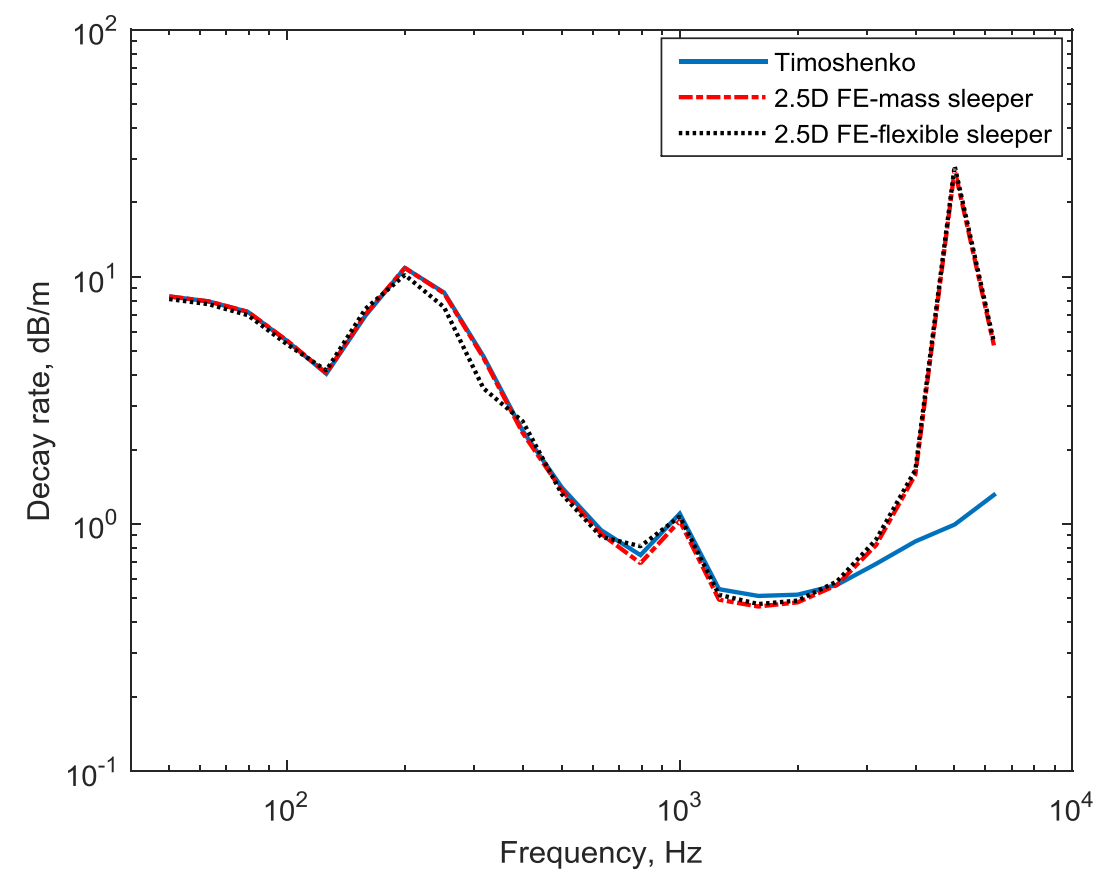

Figure 23 Comparison of the predicted vertical track decay rate of track B

\subsection{The number of the springs used to represent the rail pad}

The influence of the number of the springs used to represent each rail pad is explored in this section. At each sleeper, when using the flexible sleeper model, a single line of three springs across the rail foot has been used for the rail pad in Section 3 (see Figure 6(b)). Various other configurations of springs are considered in this section, as shown in Figure 25(a): a single spring, a different set of three springs with the outer springs at the edge of the rail foot, and eleven springs (i.e. all the node points on the bottom of the rail in the 2.5D FE mesh). In addition, multiple sets of springs are considered in the longitudinal direction of the rail. Instead of a single line of springs at each support, three parallel lines are used, separated by $\pm 0.06 \mathrm{~m}$. This distance is chosen to allow a rail pad length of $0.18 \mathrm{~m}$ to be divided equally. The stiffness of each spring is again determined by the length of the rail foot, in both transverse and longitudinal directions, to which it is attached. 
(a)

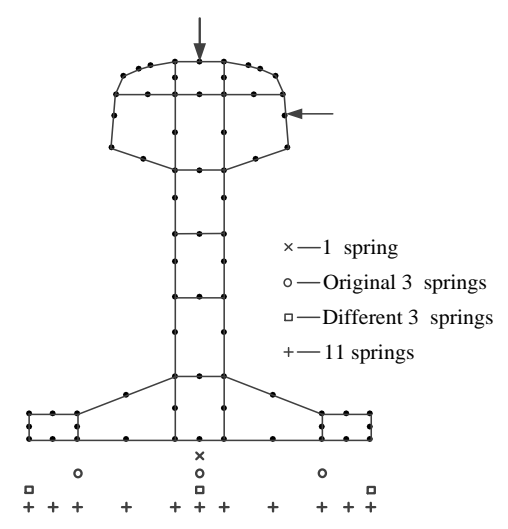

(b)

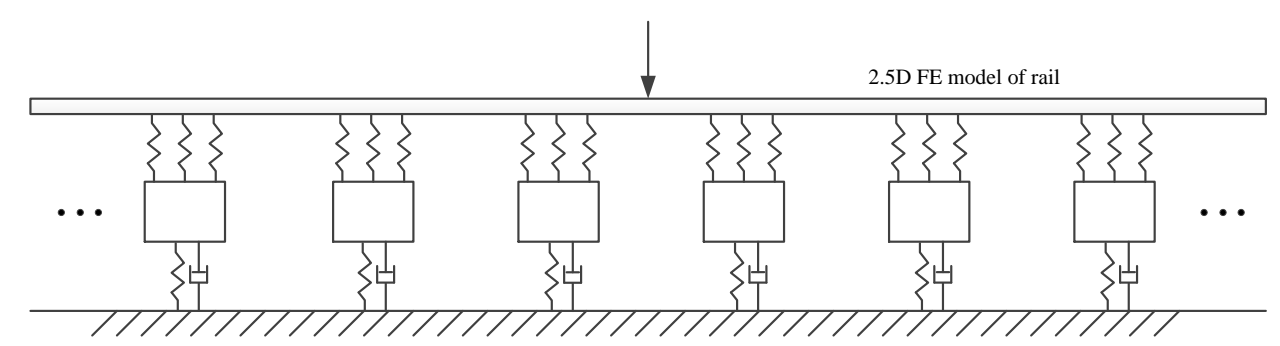

Figure 24 Model of a discretely supported track. (a) Positions of different configurations of springs across the rail foot in the transverse direction; (b) positions of the springs in the longitudinal direction

The effects of using different numbers of springs on the vertical mobility of track A are presented in Figure 25. The number of springs located across the rail foot has little influence on the vertical mobility, although the result for a single spring is slightly different. A line of three springs is sufficient to represent the rail pad but they should be chosen appropriately: the result is affected when the outer springs are located at the edge of the rail foot. There is also little change in the mobility when the springs are distributed along the rail, as shown in Figure 25(b). The corresponding effects on the decay rate are presented in Figure 26, where it is shown that the influence on the decay rate is also limited. Although it was found in the literature [36-39] that inclusion of multiple springs along the length of the rail strongly affects the amplitude at the pinned-pinned resonance, this is not found in the current results. This is due to the inclusion here of a damping loss factor on the rail, which has been included to improve the agreement with the measured decay rates [1], but which also avoids an unrealistically sharp peak occurring at the pinned-pinned frequency.

The lateral response of the rail at low frequencies is influenced by both the lateral and vertical stiffness of the springs. For the lateral stiffness, the lateral position and number of the springs 
have negligible effect. However, when the rail is excited laterally, the vertical stiffness of the springs also influences the rail response through the torsion of the rail foot. Thus, in varying the position and number of the springs, it is changes to the latter that are being studied. Nevertheless, for simplicity in this study the number of vertical and lateral springs are kept the same. The results for the lateral direction in this case are presented in Figure 27 and Figure 28. No results are shown for a single spring, which would not contribute any rotational stiffness. When three springs are used with springs located at the edge of the rail this leads to a change in the mobility, particularly at low frequency due to the larger rotational pad stiffness introduced in this case. It can be concluded that if the springs in a single line are appropriately selected, it is sufficient to use three suitably-placed springs to capture the behaviour of the rail pad. For track B, with a soft rail pad, the trends are similar so the corresponding results and analysis are not shown here.
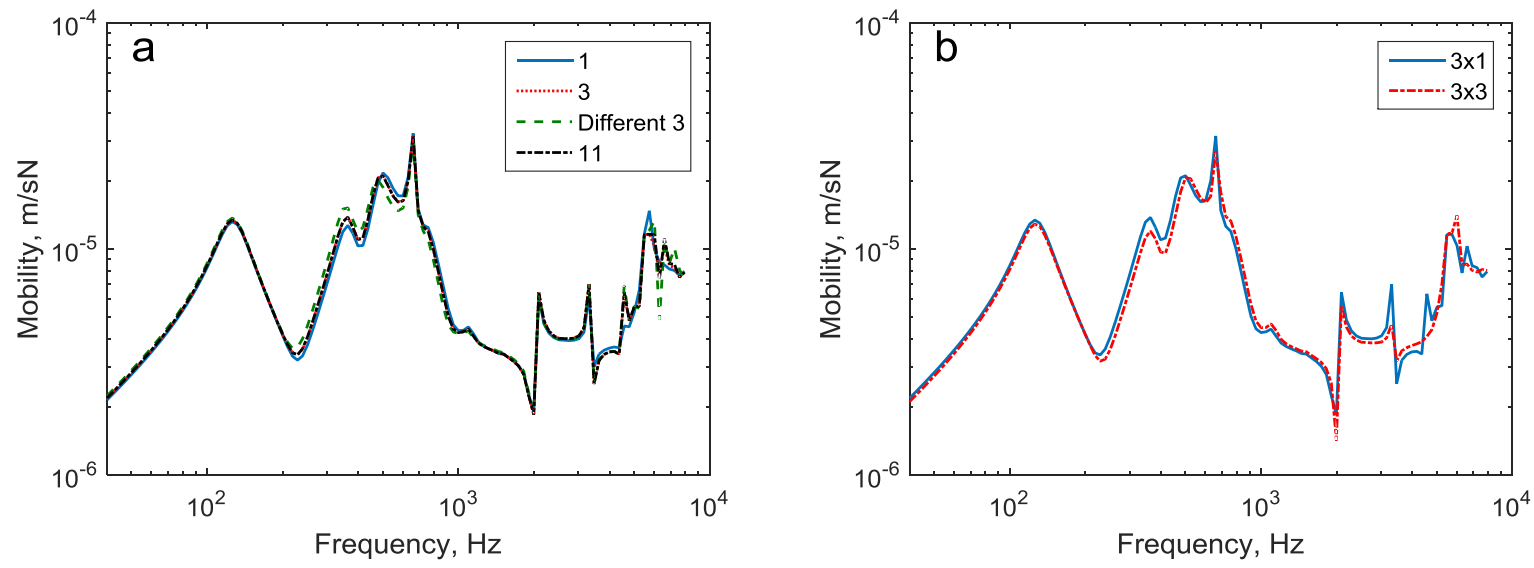

Figure 25 Effects of number of springs used for the rail pad on the predictions for the vertical point mobility of track A. (a) Varying number of springs in transverse direction; (b) varying number of springs in longitudinal direction
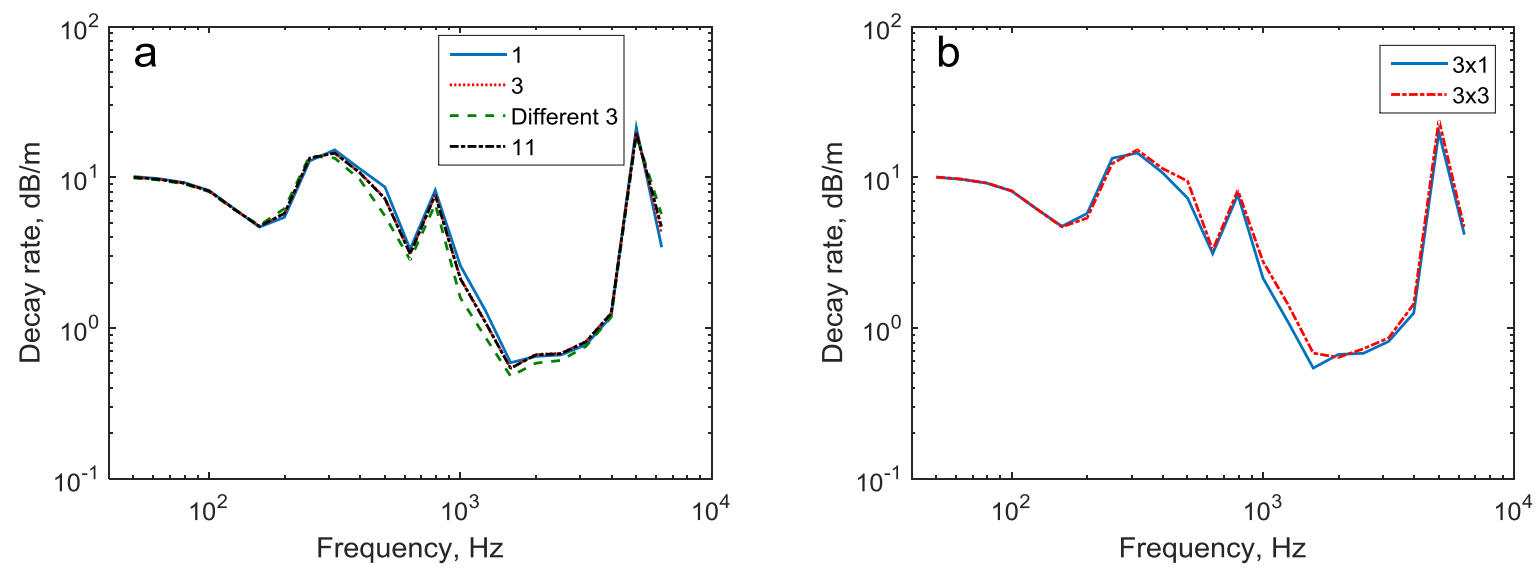

Figure 26 Effects of number of springs used for the rail pad on the predictions for the vertical decay rate of track A. (a) Varying number of springs in transverse direction; (b) varying number of springs in longitudinal direction 

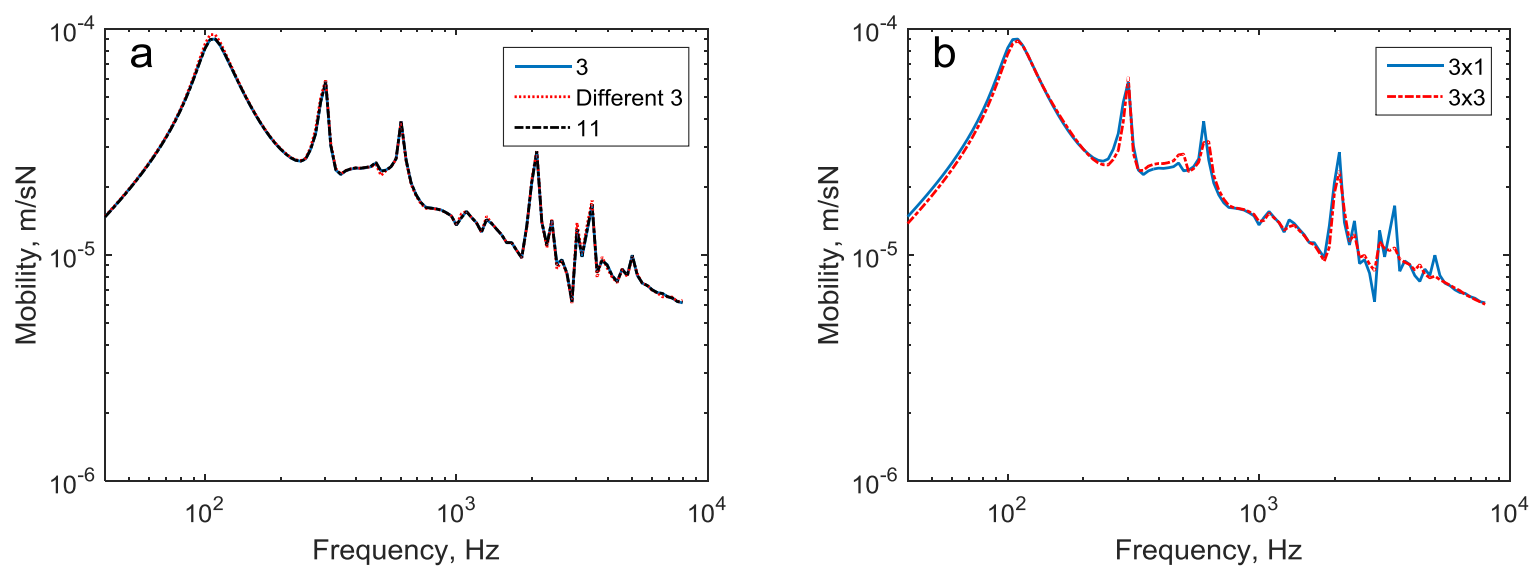

Figure 27 Effects of number of springs used for the rail pad on the predictions for the lateral vibration of track A. (a) Varying number of springs in transverse direction; (b) varying number of springs in longitudinal direction
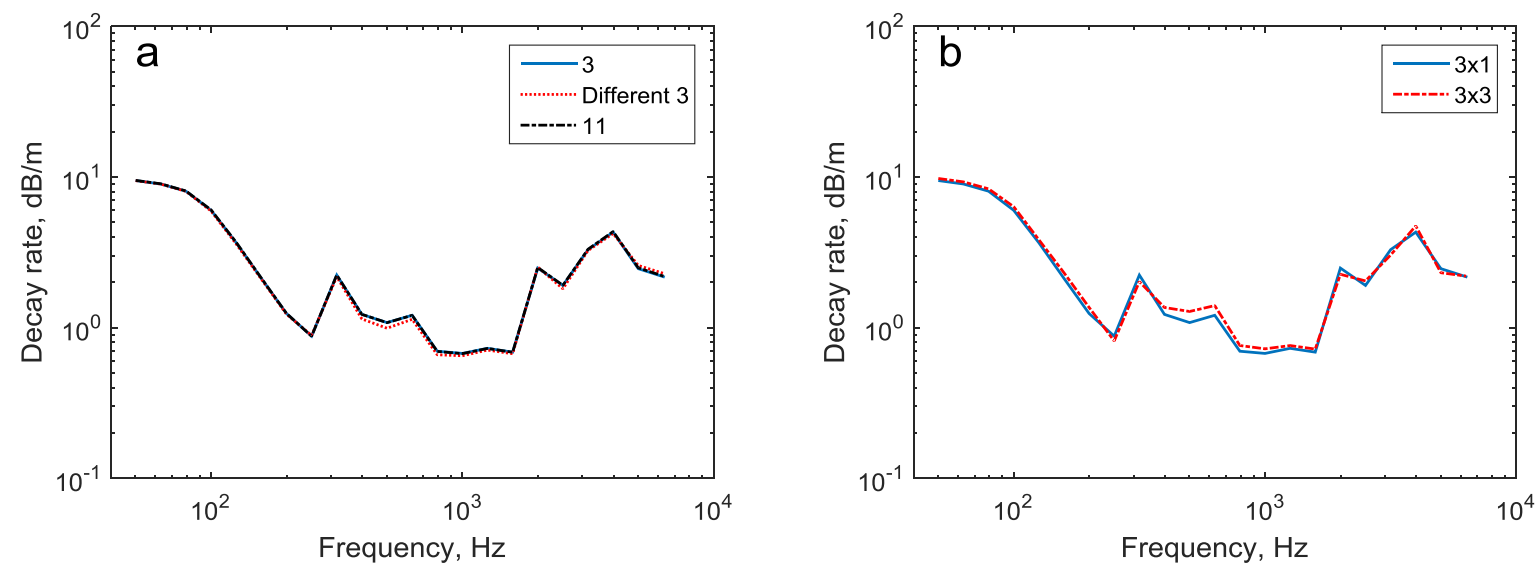

Figure 28 Effects of number of springs used for the rail pad on the predictions for the lateral decay rate of track A. (a) Varying number of springs in transverse direction; (b) varying number of springs in longitudinal direction

\section{Conclusions}

A model of a discretely supported track including cross-section deformation is presented which is based on the coupling of the rail and sleepers by a receptance coupling method. The rail is modelled by a $2.5 \mathrm{D}$ finite element approach, while the flexible sleepers with ballast support are represented by an analytical model of a Timoshenko beam. They are connected to each other by means of a line of springs beneath the rail foot representing the rail pads. The dynamic response is investigated by using this track model and compared with measurement results from two tracks with different rail pad stiffnesses. 
The new track model shows clear advantages for the vibration of a track with a stiff rail pad (vertical stiffness $400 \mathrm{MN} / \mathrm{m}$ ). It is found that the predicted vertical and lateral dynamic behaviour of the track gives good agreement with the measured results for point mobility and track decay rate.

For the dynamic response of a track with a soft rail pad (vertical stiffness $90 \mathrm{MN} / \mathrm{m}$ ) for both vertical and lateral excitation, the new track model gives predictions that agree very well with the measured data in the whole frequency range up to $6 \mathrm{kHz}$. Nevertheless, the conventional Timoshenko beam model is sufficient to determine the vertical dynamic behaviour up to $5 \mathrm{kHz}$ due to the presence of the soft rail pad.

The inclusion of the flexibility of the sleeper in the coupled track model gives improved results for the mobility and track decay rate for a track with stiff rail pads. However, for soft rail pads, the flexible behaviour of the sleeper has little influence on the rail vibration. In this case, a conventional mass model for the sleeper is sufficient.

The number of springs employed to represent each rail pad does not have a significant influence on the predicted response of the track when multiple springs are used. Three springs across the width of the sleeper are sufficient as long as they are appropriately placed underneath the rail foot. Extending this to three parallel lines has little effect on the response.

\section{Acknowledgements}

The work described here has been supported by the EPSRC under the programme grant EP/M025276/1, 'The science and analytical tools to design long life, low noise railway track systems (Track to the Future)'.

\section{References}

[1] D. Thompson, Railway noise and vibration mechanisms, modelling and means of control, Elsevier, 2008.

[2] P. J. Remington, Wheel/rail noise-part 1: characterization of the wheel/rail dynamic system, J Sound Vib. 46 (1976) 359-380.

[3] P. J. Remington, Wheel/rail rolling noise I: theoretical analysis, J. Acoust. Soc. Am. 81 (1987) 1805-1823.

[4] K.L. Knothe, S.L. Grassie, Modelling of railway track and vehicle/track interaction at high frequencies, Veh Syst Dyn. 22 (1993) 209-262. 
[5] D.J. Thompson, N. Vincent, Track dynamic behaviour at high frequencies. Part 1: theoretical models and laboratory measurements, Veh Syst Dyn Supplement. 24 (1995) 86-99.

[6] D. Kostovasilis, D.J. Thompson, M.F.M. Hussein, A semi-analytical beam model for the vibration of railway tracks, J Sound Vib. 393 (2016) 321-337.

[7] D.J. Thompson, Experimental analysis of wave propagation in railway tracks, J Sound Vib. 203 (1997) 867-888.

[8] T.X. Wu, D.J. Thompson, A double Timoshenko beam model for vertical vibration analysis of railway track at high frequencies, J Sound Vib. 224 (1999) 329-348.

[9] T.X. Wu, D.J. Thompson, Analysis of lateral vibration behaviour of railway track at high frequencies using a continuously supported multiple beam model, J. Acoust. Soc. Am. 106 (1999) 1369-1376.

[10] S.L. Grassie, Rail corrugation: characteristics, causes, and treatments, Proceedings of the Institution of Mechanical Engineers, Part F: J Rail Rapid Transit. 223 (2009) 581596.

[11] S. L. Grassie, R. W. Gregory, D. Harrison, K. L. Johnson, The dynamic response of railway track to high frequency vertical excitation, Journal of Mechanical engineering science. 24 (1982) 77-90.

[12] E. Tassilly, Propagation of bending waves in a periodic beam, International Journal of Engineering Science. 25 (1987) 85-95.

[13] K. Ono, M. Yamada, Analysis of railway track vibration, J Sound Vib. 130 (1989) 269-297.

[14] M.A. Heckl, Railway noise-Can random sleeper spacings help? ACUSTICA. 81 (1995) 559-564.

[15] T.X. Wu, D.J. Thompson, Application of a multiple-beam model for lateral vibration analysis of a discretely supported rail at high frequencies, J. Acoust. Soc. Am. 108 (2000) 1341-1344.

[16] M.A. Heckl, Coupled waves on a periodically supported Timoshenko beam, J Sound Vib. 252 (2002) 849-882.

[17] D.J. Thompson, Wheel-rail noise generation, part III: rail vibration, J Sound Vib.161 (1993) 421-446.

[18] J. Ryue, D.J. Thompson, P.R. White, D.R. Thompson, Investigations of propagating wave types in railway tracks at high frequencies, J Sound Vib. 315 (2008) 157-175. 
[19] K.L. Knothe, Z. Strzyzakowski, K. Willner, Rail vibrations in the high frequency range, J Sound Vib. 169 (1994) 111-123.

[20] B. Betgen, G. Squicciarini, D.J. Thompson, On the prediction of rail cross mobility and track decay rates using Finite Element Models, EuroNoise 2015, Maastricht, Netherland, 2015.

[21] I. Bartoli, A. Marzani, F. Lanza di Scalea, E. Viola, Modelling wave propagation in damped waveguides of arbitrary cross-section, J Sound Vib, 295 (2006) 685-707.

[22] C.-M. Nilsson, Waveguide finite elements applied on a car tyre, Doctoral thesis, MWL, KTH, Stockholm, 2004.

[23] C.-M. Nilsson, C.J.C. Jones, D.J. Thompson, J. Ryue, A waveguide finite element and boundary element approach to calculating the sound radiated by railway and tram rails, J Sound Vib. 321 (2009) 813-836.

[24] B. Aalami, Waves in prismatic guides of arbitrary cross section, J Appl Mech Trans. 40(1973) 1067-1072.

[25] L. Gavric, Finite element computation of dispersion properties of thin-walled waveguides, J Sound Vib. 173 (1994) 113-124.

[26] U. Orrenius, S. Finnveden, Calculation of wave propagation in rib-stiffened plate structures, J Sound Vib. 198 (1996) 203-224.

[27] L. Gavric, Computation of propagative waves in free rail using a finite element technique, J Sound Vib. 185 (1995) 531-543.

[28] W. Li, R.A. Dwight, T. Zhang, On the study of vibration of a supported railway rail using the semi-analytical finite element method, J Sound Vib. 345 (2015) 121-145.

[29] R.A. Clark, P.A. Dean, J.A. Elkins, S. G. Newton, An investigation into the dynamic effects of railway vehicles running on corrugated rails, Journal of Mechanical Engineering Science. 24 (1982) 65-76.

[30] S.L. Grassie, S.J. Cox, The dynamic response of railway track with flexible sleeper to high frequency vertical excitation, Proceedings of the Institution of Mechanical Engineers. 198D (1984) 117-124.

[31] J.C.O. Nielsen, A.Igeland, Vertical dynamic interation between train and trackinfluence of wheel and track imperfections, J Sound Vib. 187 (1995) 825-839.

[32] S. L. Grassie, Dynamic modelling of concrete railway sleepers J Sound Vib. 187 (1995) 799-813. 
[33] D.J. Thompson, B. Hemsworth, N. Vincent, Experimental validation of the TWINS prediction program for rolling noise, Part 1: description of the model and method, $\mathrm{J}$ Sound Vib. 193 (1996) 123-135.

[34] D.J. Thompson, M.H.A. Janssens, Track Wheel Interaction Noise Software, Version 2.4. Theoretical manual, TPD-HAG-MEMO-960343, 1996.

[35] L. Gry, Dynamic modelling of railway track based on wave propagation, J Sound Vib. 195 (1996) 477-505.

[36] R. Ferrara, G. Leonardi, F. Jourdan, A contact-area model for rail-pads connections in 2-D simulations: sensitivity analysis of train-induced vibrations, Veh Syst Dyn. 51 (2013) 1342-1362.

[37] M. Oregui, Z. Li, R. Dollevoet, An investigation into the vertical dynamics of tracks with monoblock sleepers with a 3D finite-element model, J Rail Rapid Transit. 230 (2016) 891-908.

[38] T. Mazilu, M. Leu, Impact of the rail-pad multi-discrete model upon the prediction of the rail response, IOP Conference Series: Materials Science and Engineering. 227 (2017) 012079.

[39] B. Blanco, A. Alonso, L. Kari, N. Gil-Negrete, J.G. Gimenez, Distributed support modelling for vertical track dynamic analysis, Veh Syst Dyn. 56 (2018) 529-552.

[40] Q. Li, D.J. Thompson, M.G.R. Toward, Estimation of track parameters and wheel-rail combined roughness from rail vibration, J Rail Rapid Transit. DOI: 10.1177/ $0954409717720839,2017$.

[41] H. Priestley, Introduction to complex analysis, Oxford University Press, $2^{\text {nd }}$ edition, 2003.

[42] D.J. Thompson, J.W. Verheiij, The dynamic behaviour of rail fasteners at high frequencies, Appl Acoust. 52 (1997) 1-17.

[43] D.J. Thompson, W.J. van Vliet, J.W. Verheiij, Developments of the indirect method for measuring the high frequency dynamic stiffness of resilient elements, J Sound Vib. 213 (1998) 169-188.

[44] D. Kostovasilis, Analytical modelling of the vibration of railway track, $\mathrm{PhD}$ thesis, University of Southampton, UK, 2017.

[45] N. Fremion, J.P. Goudard, N. Vincent, Improvements of ballast and sleeper description in TWINS, Step 1: experimental characterization of ballast properties. Vibratec report 072.028a, 1996. 
[46] EN 15461:2008+A1:2010. Railway applications. Noise emission. Characterization of the dynamic properties of track selections for pass by noise measurements. Centre for European Standardization.

[47] L. Le Pen, G. Watson, W. Powrie, G. Yeo, P. Weston, C. Roberts, The behaviour of railway level crossings: Insights through field monitoring, Transportation Geotechnics. 1 (2014) 201-213. 